\title{
Development of ternary diagrams for estimating water retention properties using geostatistical approaches
}

\author{
T.B. Ramos ${ }^{\text {a,*, }}$, A. Horta ${ }^{\text {b }}$, M.C. Gonçalves ${ }^{\text {a,c }}$, J.C. Martins ${ }^{c}$, L.S. Pereira ${ }^{a}$ \\ a CEER, Institute of Agronomy, University of Lisbon, Tapada da Ajuda, 1349-017 Lisbon, Portugal \\ b Department of Environmental Sciences, Faculty of Agriculture and Environment, The University of Sidney, Eveleigh, NSW 2015, Australia \\ c INIAV, National Institute of Agronomic and Veterinarian Research, Av. República, 2784-505 Oeiras, Portugal
}

\section{A R T I C L E I N F O}

Article history:

Received 21 August 2013

Received in revised form 12 April 2014

Accepted 13 April 2014

Available online 6 May 2014

\section{Keywords:}

Field capacity

Geostatistics

Soil texture

Pedotransfer functions

Wilting point

\begin{abstract}
A B S T R A C T
Most pedotransfer functions (PTFs) have adopted soil texture information as the main predictor to estimate soil hydraulic properties, whether inputs are defined in terms of the relative proportion of different grain size particles or texture-based classifications. The objective of this study was to develop ternary diagrams for estimating soil water retention $(\theta)$ at -33 and $-1500 \mathrm{kPa}$ matric potentials, corresponding to the field capacity and wilting point, respectively, from particle size distribution using two geostatistical approaches. The texture triangle was divided into a $1 \%$ grid of soil texture composition resulting in 4332 different soil textures. Measured soil water retention values determined in 742 soil horizons/layers located in Portugal were then used to develop and validate the hydraulic ternary diagrams. The development subset included two-thirds of the data, and the validation subset the remaining samples. The measured soil water content values were displayed in the ternary diagram according to the coordinates given by the particles size distribution determined in the same soil samples. The volumetric water content values were then predicted for the entire ternary diagram using two different geostatistical interpolation algorithms (ordinary kriging and the empirical best linear unbiased predictor). Uncertainty analysis resulted in a root mean square error below 0.040 and $0.034 \mathrm{~cm}^{3} \mathrm{~cm}^{-3}$ when comparing the interpolated water contents at -33 and $-1500 \mathrm{kPa}$ matric potential values, respectively, with the measured ones included in the validation dataset. The estimation variance calculated with both methods was also considered to access the uncertainty of the predictions. The available water content of Portuguese soils was then derived from $\theta_{-33} \mathrm{kPa}$ and $\theta_{-1500 \mathrm{kPa}}$ ternary diagrams developed with both approaches. The hydraulic ternary diagrams may thus serve as simplified tools for estimating water retention properties from particle size distribution and eventually serve as an alternative to the traditional statistical regression and data mining techniques used to derive PTFs.
\end{abstract}

(c) 2014 Elsevier B.V. All rights reserved.

\section{Introduction}

Modern hydrologic modeling studies require a quantitative and precise understanding of soil hydraulic properties. That information is essential for a wide range of applications, such as research on soil and water conservation, irrigation scheduling, solute transport, virus and bacterial migration, plant growth, and plant stress. However, classic methods for direct measurement of soil hydraulic properties (Dane and Topp, 2002) are known to be costly, time consuming, and impractical for large-scale applications in which many samples are required to quantify the spatial and temporal variability of those properties. Hence, pedotransfer functions (PTFs) have been developed as an alternative to classical methods to indirectly estimate soil hydraulic properties from basic soil physical and chemical properties (Bouma,

\footnotetext{
* Corresponding author. Tel.: + 351214403500 ; fax: + 351214416011.

E-mail address: tiago_ramos@netcabo.pt (T.B. Ramos).
}

1989; McBratney et al., 2002; Pachepsky and Rawls, 2004; Vereecken et al., 1989), thus overcoming some of the limitations mentioned earlier, especially when the objective is to characterize soil hydraulic properties at large scales.

Most of the available PTFs use soil-texture-based information as the main predictor to estimate the hydraulic behavior of soils. This popular option is justified by the fact that soil texture characteristics are among the most easily measured soil properties, and also by the assumption that soil texture is the dominant soil variable in determining hydraulic properties, while other soil variables, such as bulk density or organic matter content, have a secondary effect (Twarakavi et al., 2010). The simplest texture based PTFs were developed to provide estimates of average soil water retention properties or hydraulic parameters for different texture classes (e.g., Al Majou et al., 2008; Bruand et al., 2003; Ramos et al., 2013; Schaap and Leij, 1998; Wösten et al., 1995). More complex functions have also been developed by relating the particle size limits of the soil constituents to soil hydraulics using multiple regression analysis or data mining tools (e.g., Gupta and Larson, 1979; 
Haghverdi et al., 2012; Nemes et al., 2006; Saxton et al., 1986; Schaap et al., 2001). Although the hierarchical approaches followed in many of those studies showed that the accuracy of PTFs improved considerably when other variables (usually bulk density), rather than soil texture information alone, were used also as predictors, texture based PTFs have been considered to also provide reasonably accurate estimates of soil hydraulic properties for many research and technical applications (Vereecken et al., 2010).

Soil texture is normally represented in a ternary diagram, function of sand, silt and clay percentages, where the limits of the texture classes vary according to the texture classification system used. However, the soil texture triangle has also had more applications than simply grouping texture information data, namely it has also been used as a tool to estimate soil hydraulic properties. Saxton et al. (1986) divided the soil texture triangle into grids of $10 \%$ sand and $10 \%$ clay content increments to develop texture based PTFs for generalized predictions of soil hydraulic properties in each grid cell. Later, Saxton and Rawls (2006) updated the previous work to further include the effect of organic matter, bulk density, gravel, and salinity in their model and provide a broadly applicable predictive system. The developed model has been successfully applied to a wide variety of analysis, particularly those related to agricultural hydrology and water management, since estimates do not involve complex mathematical methods, and the texture triangle serves as a familiar tool to users for estimating the soil water characteristics. Twarakavi et al. (2010) also focused on the relations between the texture triangle and soil hydraulic properties. Those authors estimated soil hydraulic properties throughout the entire soil texture triangle as a function of sand, silt, and clay contents using the ROSETTA PTFs (Schaap et al., 2001) such that the various soil texture possibilities (i.e., combinations of sand, silt, and clay percentages) were considered. They then concluded that although the soil texture triangle was qualitatively very similar to the soil hydraulic triangle, differences existed especially for soils where capillary forces dominate the flow throughout the soils. Bormann (2007) took those studies one step forward and performed water balance calculations for the entire space of the soil texture triangle, after dividing it into $1 \%$ grid cells and applying Rawls and Brakensiek (1985) PTFs for obtaining the soil hydraulic properties.

Following those studies on the prediction of soil hydraulic properties for the entire space of the soil texture triangle, we propose a novel geostatistical approach to obtain the spatial distribution of water retention values (the field capacity and wilting point) available in a soil database (Gonçalves et al., 2011). Our work presents the application of two geostatistical methods, one using ordinary kriging (Goovaerts, 1999, 2001) and the other using the empirical best linear unbiased predictor (EBLUP) based on residual maximum likelihood (REML) estimation of the spatial variance model as proposed by Lark et al. (2006). This second method includes the texture PTF as a trend model. Although there are countless applications of these methods in soil science, as far as we know these estimators have never been used as PTFs to actually derive soil hydraulic properties from basic soil data. To proceed with this study, three very basic concepts were established:

(i) Soil texture and soil water retention properties available in the database were assumed as being determined in the same sample. This is usually not the case in most PTFs where the predictors used in their development, although measured in the same soil horizon, are not always determined directly on the soil samples used for measuring the hydraulic properties. As referred by Vereecken et al. (2010), this becomes more important as the spatial and temporal variability of additional soil information increases and the information content is not related anymore to the samples on which the hydraulic properties were determined. Thus, taking into account the size of the database used in this study, the error resulting from this assumption was not considered to be relevant. (ii) Soil texture was considered the main predictor to estimate soil hydraulic properties. As mentioned earlier, this is the main assumption sustaining all texture based PTFs since these two soil properties normally exhibit a high correlation.

(iii) The spatial continuity of soil hydraulic properties along the soil texture triangle can be described by means of a variogram. Taking into account that soil texture is the main soil property considered when grouping soils having similar water retention curves (Bruand et al., 2003; Ramos et al., 2013; Wösten et al., 1995), and that the soil texture triangle and the soil hydraulic triangle can be relatively similar (Twarakavi et al., 2010), we assumed that there could be a spatial dependence of soil hydraulic properties, at least within the limits of each soil texture class.

The objective of this study is thus to develop ternary diagrams for estimating point specific water retention values (the field capacity and wilting point) of Portuguese soils using two geostatistical approaches: ordinary kriging (OK), and the empirical best linear unbiased predictor (EBLUP). The available water capacity was later computed from both ternary diagrams derived from each approach.

\section{Material and methods}

\subsection{Soil dataset}

The ternary diagrams were developed for estimating the field capacity and wilting point of Portuguese soils from particle size distribution. The field capacity and wilting point were here assumed to correspond to the water retention values at -33 and $-1500 \mathrm{kPa}$, respectively (Romano and Santini, 2002). The data was extracted from the PROPSOLO soil database (Gonçalves et al., 2011), which gathers all information on soil hydraulic and pedological properties from soil profiles obtained from research projects and academic studies performed at the Portuguese National Institute of Agronomic and Veterinarian Research (formerly Estação Agronómica Nacional). This database contains practically all of the existing knowledge on the soil hydraulic properties of Portuguese soils.

The data included information on soil texture and water retention properties of 742 horizons/layers studied in 346 soil profiles located in Portugal between 1977 and 2012 (Fig. 1). It comprised 331 topsoil (0-30 cm depth) and 411 subsoil (>30 cm depth) horizons. The soil reference groups (FAO, 2006) represented were Fluvisols (36.4\%), Luvisols (29.5\%), Vertisols (9.8\%), Cambisols (8.7\%), Calcisols (6.6\%), Anthrosols (4.0\%), Arenosols (1.4\%), Podzols (0.9\%), Regosols (0.9\%), Ferralsols (0.6\%), Leptosols (0.6\%), and Planosols (0.6\%).

The data was randomly divided into two subsets, a development set composed of two-thirds of the data (495 horizons/layers), and a validation set with the remaining one-third of the data (247 horizons/layers). Table 1 presents the main physical and chemical properties of the two datasets. The particle size distribution was obtained using the pipette method for particles having diameters $<2 \mu \mathrm{m}$ (clay) and between 20-2 $\mu \mathrm{m}$ (silt), and by sieving for particles between 200 and $20 \mu \mathrm{m}$ (fine sand) and between 200 and $2000 \mu \mathrm{m}$ (coarse sand). These textural classes follow the Portuguese classification system (Gomes and Silva, 1962) and are based on the International Soil Science Society (ISSS) particle limits (Atterberg scale). The dry bulk density $\left(\rho_{\mathrm{b}}\right)$ was obtained by drying volumetric soil samples $\left(100 \mathrm{~cm}^{3}\right)$ at $105^{\circ} \mathrm{C}$ for $48 \mathrm{~h}$. The gravimetric water content at $-33 \mathrm{kPa}$ matric potential was determined on undisturbed soil samples $\left(100 \mathrm{~cm}^{3}\right)$ using suction tables (Romano et al., 2002; used in 494 horizons/layers) or the pressure plate apparatus (Dane and Hopmans, 2002; used in 212 horizons/layers). The gravimetric water content at $-1500 \mathrm{kPa}$ matric potential was also determined on undisturbed soil samples $\left(100 \mathrm{~cm}^{3}\right)$ using the pressure plate apparatus. Then, the volumetric water content for each horizon/layer and each matric potential was computed from the gravimetric water contents and the bulk density of the corresponding horizon/layer. 


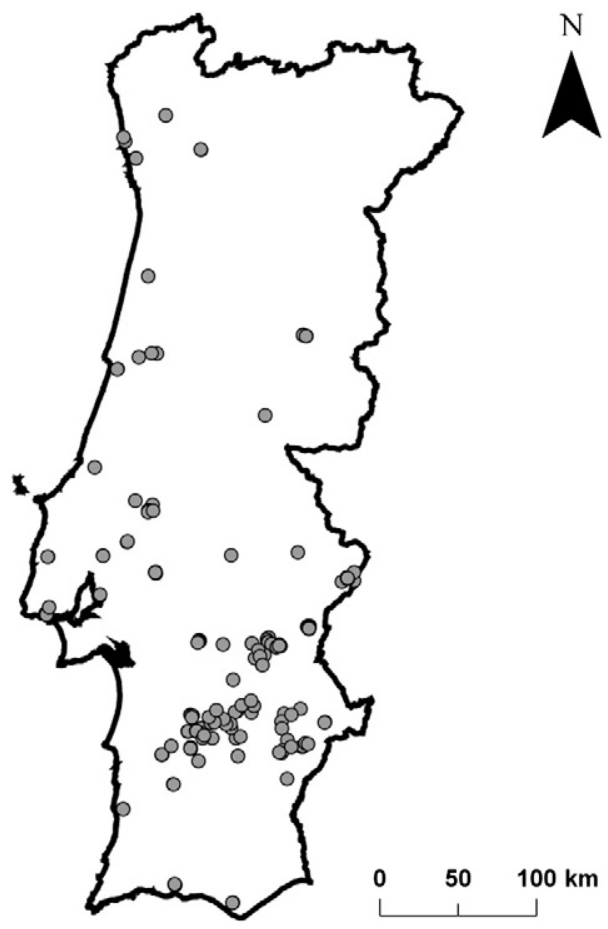

Fig. 1. Location of the soil profiles.

In the case of 36 soil horizons/layers where the volumetric water content at $-33 \mathrm{kPa}$ matric potential was not readily available, the missing values were estimated by introducing values derived from the fitted van Genuchten model (1980) to each individual water retention curve, also available in the soil database for all soil horizons/layers. The van Genuchten model describes the volumetric soil water content, $\theta\left(\mathrm{L}^{3} \mathrm{~L}^{-3}\right)$, as a function of matric potential, $\psi(\mathrm{L})$, in the following form:

$\mathrm{S}_{\mathrm{e}}(\psi)=\frac{\theta(\psi)-\theta_{\mathrm{r}}}{\theta_{\mathrm{s}}-\theta_{\mathrm{r}}}=\frac{1}{\left(1+|\alpha \psi|^{\eta}\right)^{1-1 / \eta}}$

in which $S_{\mathrm{e}}$ is the effective saturation, $\theta_{\mathrm{r}}$ and $\theta_{\mathrm{s}}$ denote the residual and saturated water contents $\left(\mathrm{L}^{3} \mathrm{~L}^{-3}\right)$, respectively, $\alpha\left(\mathrm{L}^{-1}\right)$ and $\eta(-)$ are empirical shape parameters. This procedure introduced an error to the subsequent calculations and model evaluations resulting from the non-perfect fit of the fitted model to the experimental data (RMSE $=$ $0.012 \mathrm{~cm}^{3} \mathrm{~cm}^{-3}$ ), in line with published results (e.g., Nemes and Rawls, 2006; Ramos et al., 2013). The errors were thus relatively small compared with the errors usually obtained using PTFs, and therefore, the fitted values were assumed as if they were measured.

\subsection{Development of the ternary diagrams}

\subsubsection{The interpolation domain}

Representing soil water retention values in a ternary diagram improves its interpretation for the range of possible textures. The results were therefore shown for the texture triangle, although the coordinates of the data used for interpolation purposes were converted to metric coordinates. Hence, the hydraulic triangles were developed by assuming that each water retention value available in the development dataset could be represented in a texture diagram, in the coordinates given by the particle size distribution of the corresponding samples. Since those coordinates are given by the relative proportion of the texture constituents (sand, silt, and clay), they were first transformed into a Cartesian domain (length variation in the Cartesian domain was equivalent to \% mass variation in the texture triangle), as follows:

$\mathrm{y}=\frac{\mathrm{h} \cdot \operatorname{clay}(\%)}{100}$

$x=-\left(\operatorname{sand}(\%)+\operatorname{clay}(\%) \cdot \tan \left(\frac{\alpha \pi}{180}\right)\right)$

where $y$ is the vertical coordinate, dependent only on the clay content (\%), $\mathrm{x}$ is the horizontal coordinate, function of sand and clay contents (\%), $\mathrm{h}$ is the triangle height (obtained by applying the Pythagorean theorem), and $\alpha$ is the $30^{\circ}$ angle formed between the vertical direction and the diagonal direction commonly used to represent sand content in an equilateral texture triangle. Fig. 2 shows the textural distribution of the datasets used for the development of the ternary diagrams and for their validation, the process of transformation of the texture coordinates into Cartesian coordinates, and the final distribution of the datasets in a Cartesian domain. This transformation allowed for the proportion of the texture components to be accounted for and the spatial distribution of soil data to be maintained (as if it was represented in a texture triangle). This transformation also considered the directions used to represent clay (horizontally) and sand (diagonally) contents in an equilateral texture triangle. Note that soil data could also be represented using other forms of the texture triangle, namely using a right-triangle. In this case, no transformations would be necessary since sand and clay contents could be used directly to represent water content information as it resembles a Cartesian domain. However, this type of triangle was not used in our application since it misrepresents the third component of the texture composition (silt).

After interpolation of the water retention values, the soil texture triangle was again used to limit the area of the Cartesian domain that was relevant to this study and to help in understanding water content estimates by relating them to soil texture. Hence, hydraulic triangles composed of estimates of $\theta_{-33} \mathrm{kPa}$ and $\theta_{-1500 \mathrm{kPa}}$ were obtained in the end for a $1 \%$ grid of soil texture composition, resulting in 4332 different

Table 1

Main physical and chemical properties of the datasets used in the development and validation of the ternary diagrams.

\begin{tabular}{|c|c|c|c|c|c|c|c|}
\hline \multirow[t]{3}{*}{ Statistics } & \multicolumn{4}{|c|}{ Particle size distribution } & \multirow{3}{*}{$\begin{array}{l}\text { Bulk density } \\
\frac{\left(\mathrm{g} \mathrm{cm}^{-3}\right)}{}\end{array}$} & \multicolumn{2}{|c|}{ Volumetric water contents } \\
\hline & $2000-200 \mu \mathrm{m}$ & $200-20 \mu \mathrm{m}$ & $20-2 \mu \mathrm{m}$ & $<2 \mu \mathrm{m}$ & & $\theta_{-33 \mathrm{kPa}}$ & $\theta_{-1500 \mathrm{kPa}}$ \\
\hline & \multicolumn{4}{|l|}{$(\%)$} & & \multicolumn{2}{|l|}{$\left(\mathrm{cm}^{3} \mathrm{~cm}^{-3}\right)$} \\
\hline \multicolumn{8}{|c|}{ Development set $(\mathrm{n}=495)$} \\
\hline Mean & 20.7 & 34.5 & 21.6 & 23.2 & 1.50 & 0.287 & 0.162 \\
\hline Std. deviation & 17.7 & 15.2 & 11.8 & 14.7 & 0.18 & 0.089 & 0.081 \\
\hline Minimum & 0.1 & 0.7 & 1.1 & 0.6 & 0.91 & 0.029 & 0.007 \\
\hline Maximum & 94.4 & 70.7 & 68.1 & 63.3 & 1.90 & 0.536 & 0.407 \\
\hline \multicolumn{8}{|c|}{ Validation set $(n=247)$} \\
\hline Mean & 21.4 & 34.7 & 20.5 & 23.4 & 1.52 & 0.282 & 0.158 \\
\hline Std. deviation & 17.1 & 15.4 & 12.4 & 14.3 & 0.18 & 0.086 & 0.073 \\
\hline Minimum & 0.1 & 0.8 & 0.9 & 0.1 & 0.92 & 0.029 & 0.006 \\
\hline Maximum & 94.6 & 73.6 & 60.2 & 62.2 & 1.87 & 0.535 & 0.359 \\
\hline
\end{tabular}



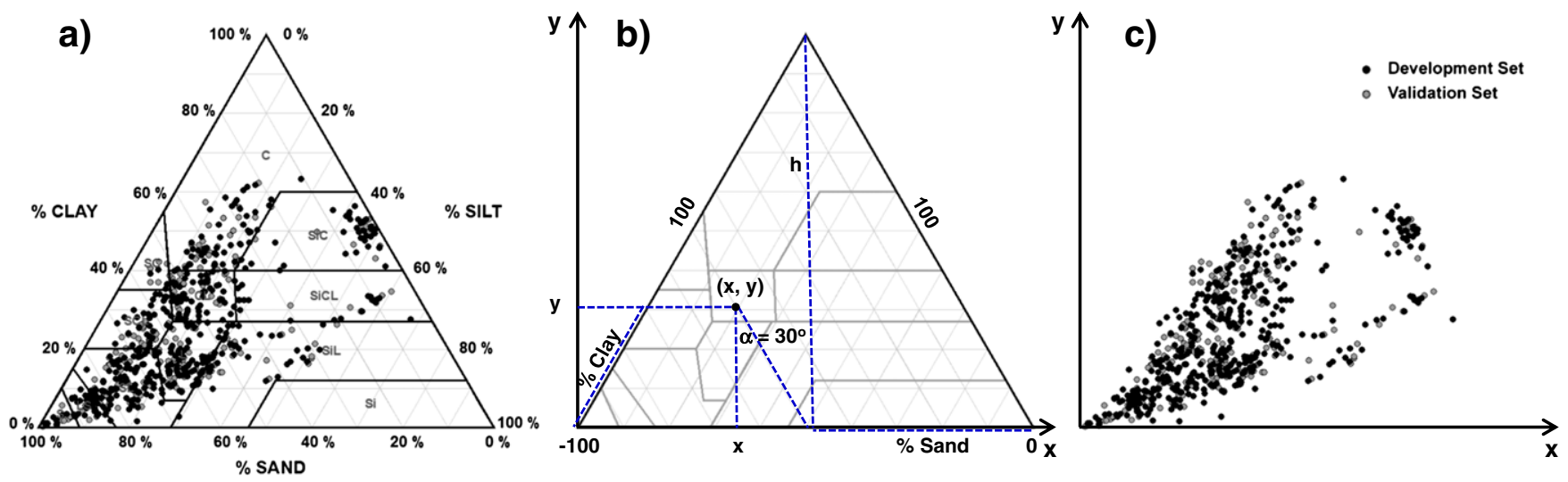

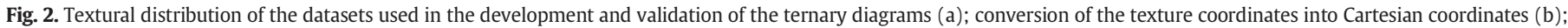
development and validation datasets in the Cartesian domain (c).

soil textures (i.e., different combinations of sand, silt, and clay percentages) and corresponding water content estimates.

\subsubsection{Geostatistical approaches for the prediction of water retention values}

To obtain the spatial distribution of soil water retention values in the texture triangle we propose to use the kriging estimator. Therefore, the first step was to obtain a valid spatial model able to describe the variation of the observed water retention values. This is usually obtained by inferring a semivariogram to which a model is fitted providing the necessary parameters required for predicting water retention in unsampled locations within the triangle.

On the first approach, the experimental semivariogram was computed using the original water retention data and fitted using a Gaussian model with nugget effect (Goovaerts, 1997). Ordinary kriging (OK) was then applied assuming that water retention variation is locally stationary responding to local changes in texture contents. The OK estimator (Journel and Huijbregts, 1978) was given as follows:

$\mathrm{Z}^{*}\left(\mathrm{x}_{0}\right)=\sum_{\mathrm{i}=1}^{\mathrm{n}} \lambda_{\mathrm{i}} \mathrm{Z}\left(\mathrm{x}_{\mathrm{i}}\right)$

where $\mathrm{Z}^{*}\left(\mathrm{x}_{0}\right)$ are the $\theta_{-33 \mathrm{kPa}}$ and $\theta_{-1500 \mathrm{kPa}}$ values to be predicted, $\mathrm{Z}\left(\mathrm{x}_{\mathrm{i}}\right)$ are the water retention values measured at location $i, n$ is the number of data points within the local neighborhood, and $\lambda_{\mathrm{i}}$ are the kriging weights (which depend on the fitted semivariogram parameters and the configuration of the values) (Webster and Oliver, 2007). The semivariogram computation and fitting, and the implementation of the kriging method were carried out with the geoMS software package (CMRP, 2000).

\section{a) variograms used with the OK approach}
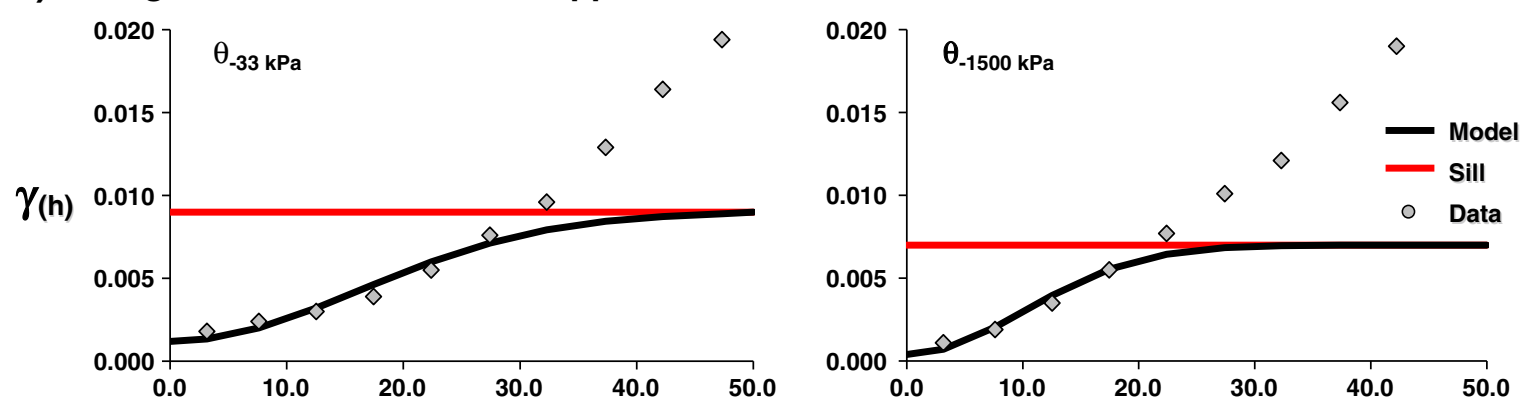

\section{b) variograms used after grouping data}
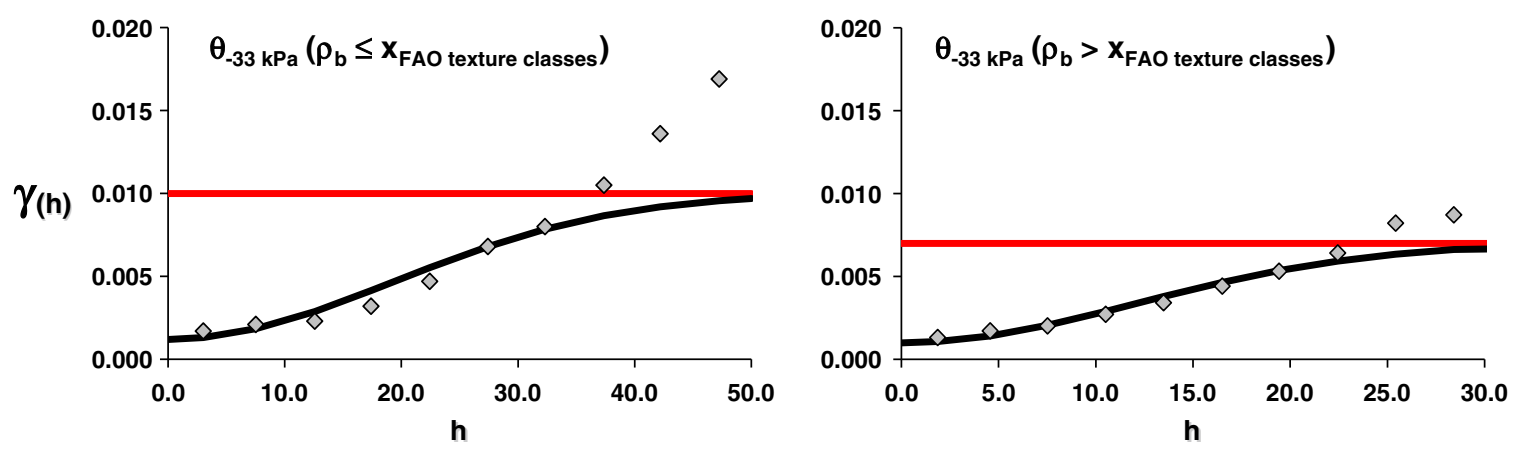

Fig. 3. Experimental semivariograms used with the ordinary kriging (OK) approach. 

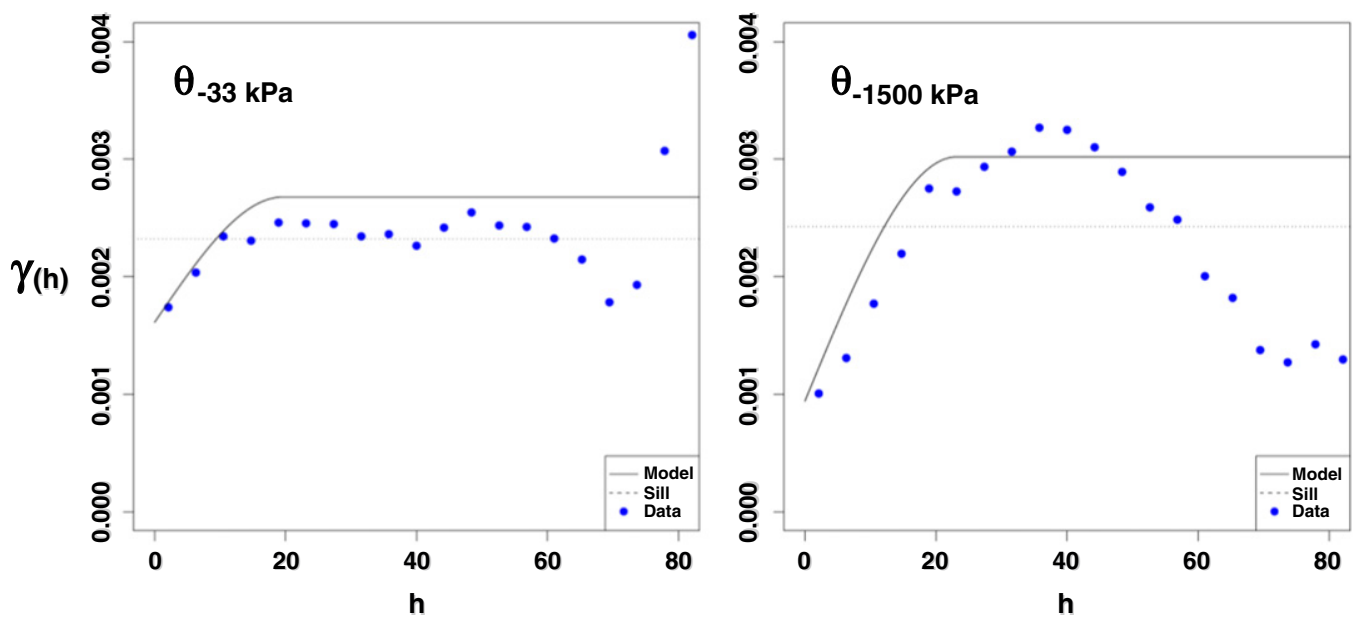

Fig. 4. Experimental semivariogram used with the empirical best linear unbiased predictor (EBLUP) approach.

The second approach proposed considered that stationarity could not be assumed even within small neighborhoods as implemented in OK. In this case, a non-stationary spatial trend was introduced. A trend model can be provided by a deterministic function able to define a large scale space pattern or by a set of physical and/or empirical covariates that are statistically significant to describe the spatial variation of the attribute $\mathrm{Z}\left(\mathrm{x}_{\mathrm{i}}\right)$. For the prediction of water retention values, the trend can be described by a physical model using a texture PTF to explain the variability of the soil water content within the texture triangle. In our case study, the texture PTF can be described as a regression relationship built with clay, sand and silt contents.
Whenever it is possible to build a trend model to explain the attribute's variability in space, the geostatistical analysis is focused on the residual component. We can evaluate the contribution of the model residuals not only to improve the water content predictions, but also to understand to which extent the PTF used as a trend explains the variations of soil water content observed at particular locations of the ternary diagram.

When a trend model is considered, the empirical best linear unbiased predictor (EBLUP) based on residual maximum likelihood (REML) can be used for water retention prediction. The best linear unbiased predictor of some variable is computed from a linear mixed model
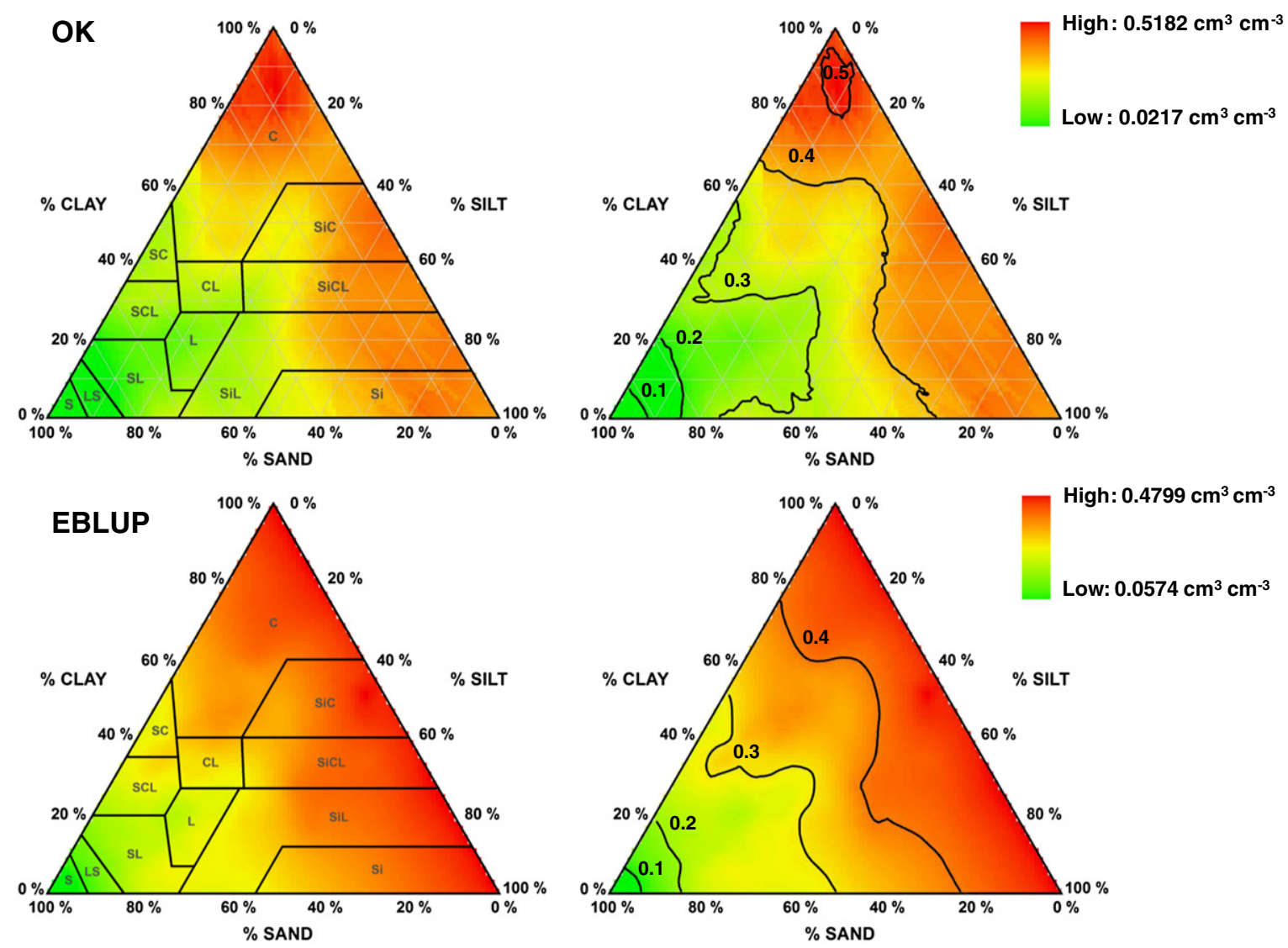

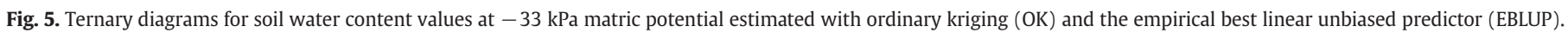
Figures on the left show the ISSS texture classes; figures on the right show the contour plots of the estimates. 
(LMM) or a model that contains fixed and random effects (Lark et al., 2006). If the fixed effect is the unknown mean then this predictor is equivalent to ordinary kriging.

In our model, the fixed effects were represented by the trend model defined by a linear equation combining clay, silt, and sand contents. The random effects were the residuals defined in the geostatistical context as a spatial dependent random variable. The LMM was given by:

$\mathrm{Z}=\mathrm{X} \tau+\mathrm{Zu}+\varepsilon$

where $\mathrm{z}$ is a vector of $\mathrm{n}$ observed responses $\left(\theta_{-33} \mathrm{kPa}\right.$ or $\left.\theta_{-1500 \mathrm{kPa}}\right), \mathrm{X}$ is an $\mathrm{n} \times \mathrm{p}$ design matrix that associates each of the $\mathrm{n}$ observations with a value of each p predictor variable/fixed effect (combination of texture variables), and $\tau$ is a vector that contains the $p$ fixed effect coefficients (describing the relationship between the fixed effects, $\mathrm{X}$, and the response, $\mathrm{z}$ ). The vector $\mathrm{u}$ contains q random effects, realizations of a variable $\mathrm{u}$ that are associated with the $\mathrm{n}$ observations by the $\mathrm{n} \times \mathrm{q}$ design matrix $Z$. The $\mathrm{u}$ is a spatially dependent random variable and the term $\varepsilon$ is a vector of independent random errors. These terms are independent of each other and contain random errors which are spatially correlated.

The LMMs were fitted using residual maximum likelihood (REML) estimation, as suggested by Lark et al. (2006). Backward elimination was used for variable selection based on the Akaike information criterion (AIC). In this study, model fitting was performed using the geoR package in $\mathrm{R}$ (Diggle and Ribeiro, 2007).

\subsection{Assessment of uncertainty of predictions}

Prediction uncertainty due to OK and EBLUP was given by the kriging variance obtained for each grid cell of the ternary diagrams.
For the OK estimator, it was computed as follows (Goovaerts, 1997; Yates and Warrick, 2002):

$\sigma_{\mathrm{k}}^{2}\left(\mathrm{x}_{0}\right)=\sum_{\mathrm{i}=1}^{\mathrm{n}} \lambda_{\mathrm{i}} \gamma\left(\mathrm{x}_{\mathrm{i}}-\mathrm{x}_{0}\right)+\mu$

where $\gamma$ is the semivariance between data pairs and $\mu$ is the Lagrange parameter accounting for the constraint on the weights $\lambda_{\mathrm{i}}$. The estimation variance of the EBLUP can be expressed generally as follows (see Lark et al. (2006) for a detailed explanation on how to compute the variance):

$\sigma_{\mathrm{k}}^{2}\left(\widetilde{\mathrm{f}}_{\mathrm{p}}-\mathrm{f}_{\mathrm{p}}\right)=\sigma^{2}\left[\mathrm{x}_{\mathrm{p}}^{\mathrm{T}}(\hat{\tau}-\tau)+\mathrm{g}_{\mathrm{o}, \mathrm{p}}^{\mathrm{T}} \mathrm{G}^{-1} \tilde{\mathrm{u}}-\mathrm{u}_{\mathrm{p}}\right]$

where the first term $x_{p}{ }^{T}(\hat{\tau}-\tau)$ accounts for the uncertainty due to estimation error of the fixed and random effects, and the second term $\mathrm{g}_{\mathrm{o}, \mathrm{p}}^{\mathrm{T}} \mathrm{G}^{-1} \tilde{\mathrm{u}}-\mathrm{u}_{\mathrm{p}}$ refers to the uncertainty of the interpolated random effect (which is in fact the kriging variance).

The ternary diagrams were also validated by comparing measured $\theta_{-33} \mathrm{kPa}$ and $\theta_{-1500 \mathrm{kPa}}$ values included in the validation dataset with OK and EBLUP estimates using various quantitative measures of accuracy, such as the determination coefficient $\left(R^{2}\right)$, the mean error $(\mathrm{ME})$, and the root mean square error (RMSE), given by:

$$
R^{2}=\left[\frac{\sum_{i=1}^{n}\left(O_{i}-\bar{O}\right)\left(P_{i}-\bar{P}\right)}{\left[\sum_{i=1}^{n}\left(O_{i}-\bar{O}\right)^{2}\right]^{0.5}\left[\sum_{i=1}^{E}\left(P_{i}-\bar{P}\right)^{2}\right]^{0.5}}\right]^{2}
$$
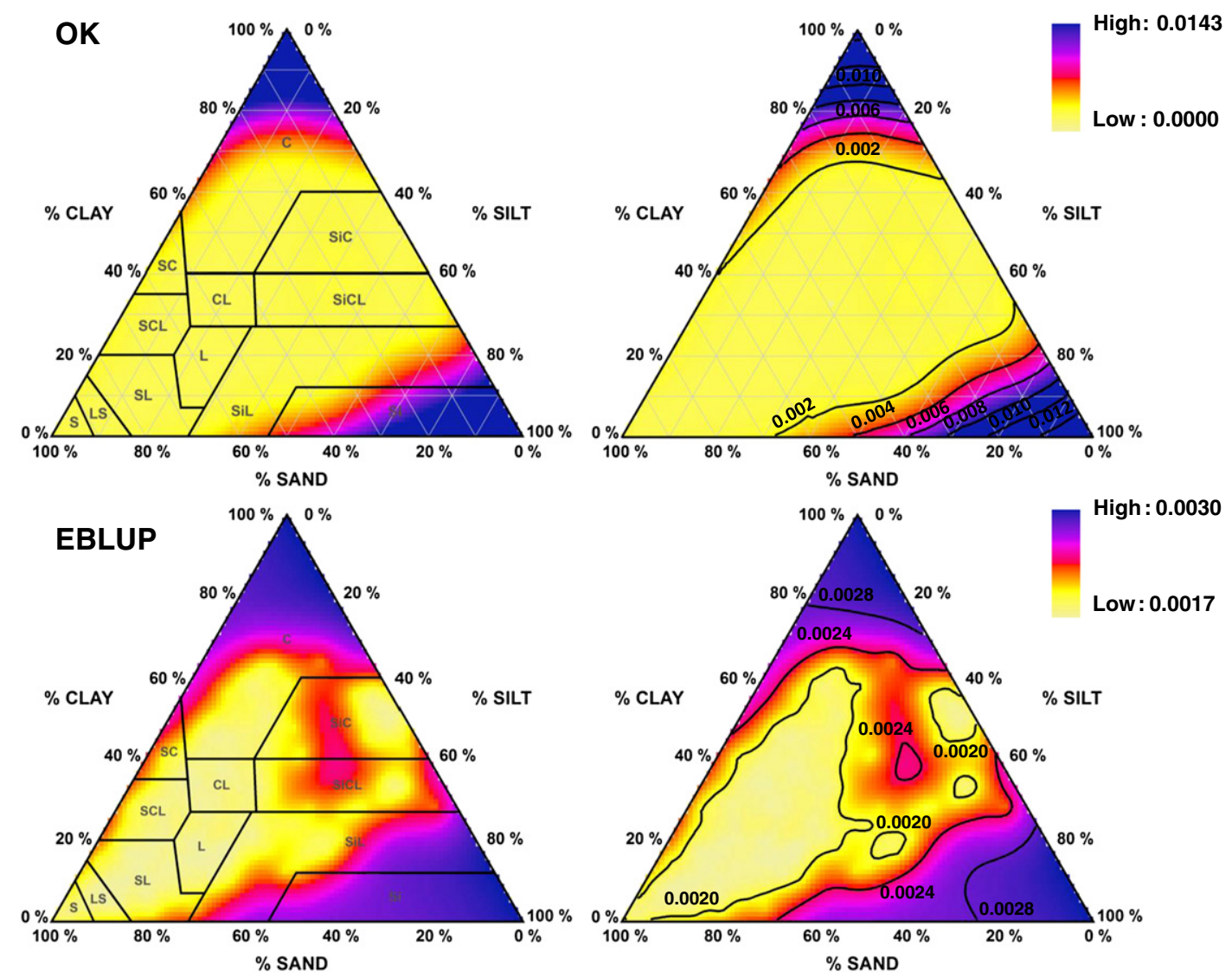

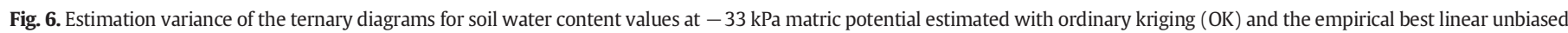
predictor (EBLUP). Figures on the left show the ISSS texture classes; figures on the right show the contour plots of the variance. 
$\mathrm{ME}=\frac{1}{\mathrm{n}} \sum_{\mathrm{i}=1}^{\mathrm{n}}\left(\mathrm{P}_{\mathrm{i}}-\mathrm{O}_{\mathrm{i}}\right)$

RMSE $=\sqrt{\frac{\sum_{i=1}^{n}\left(P_{i}-O_{i}\right)^{2}}{n-1}}$

where $\mathrm{n}$ is the number of observations, $\mathrm{O}_{\mathrm{i}}$ are the measured values, $\mathrm{P}_{\mathrm{i}}$ are the interpolation predictions, $\overline{\mathrm{O}}$ is the average of the measured values, and $\overline{\mathrm{P}}$ is the average of the interpolation predictions.

\section{Results and discussion}

\subsection{Spatial patterns of $\theta_{-33} \mathrm{kPa}$ and $\theta_{-1500 \mathrm{kPa}}$}

Fig. 3 presents the experimental and theoretical semivariograms obtained for $\theta_{-33} \mathrm{kPa}$ and $\theta_{-1500 \mathrm{kPa}}$ and used with the OK approach. The nugget values for $\theta_{-33} \mathrm{kPa}$ and $\theta_{-1500 \mathrm{kPa}}$, obtained when fitting the Gaussian model, corresponded to 15.4 and $6.1 \%$ of the total variance (C), respectively. These values explained the sampling or measurement errors, and the variation that occurs at scales too small to characterize, which cannot be described only by variations in soil texture. This can be attributed to the effect of bulk density, organic matter, soil structure, soil mineralogy, soil chemical composition, and land use and management on water retention properties. Like in the development of traditional PTFs, grouping data by considering the effect of those soil properties (Wösten et al., 2001) would likely be advantageous in order to reduce the unexplained variability found in the development of the ternary diagrams (one example where data was grouped by bulk density is given in Section 3.4). The larger nugget value found for the semivariogram of $\theta_{-33} \mathrm{kPa}$ may be further related to the different methodologies used for measuring water retention at $-33 \mathrm{kPa}$ matric potential (Schaap and Leij, 1998).

In the Gaussian variograms, the spatial continuity of $\theta_{-33} \mathrm{kPa}$ and $\theta_{-1500 \mathrm{kPa}}$ reached a range of 39.7 and $24.6 \%$ mass, respectively. Water retention values were thus correlated with samples located in neighbor texture classes (up to the distance limit given by the semivariogram), but more distanced areas of the texture triangle showed no correlation with those measured values. These findings seem to be very useful to understand the limitations of the simplest texture based PTFs, the class-PTFs (Wösten et al., 2001), when estimating water retention properties for different texture classes. These class-PTFs estimate average soil water retention properties for different texture classes based on the arithmetic (e.g., Al Majou et al., 2008; Bruand et al., 2003; Ramos et al., 2013) or geometric mean (e.g., Wösten et al., 1995, 1999) of the datasets. However, for most regions of the texture triangle water retention values may sometimes be better correlated with data included in their vicinity which may well be included in a neighbor texture class.

For the analysis performed so far we opted to fit a model to the experimental variograms not taking into consideration that the variogram given by the data is in fact unbounded. As mentioned before, this is often indicative of non-stationarity, i.e., the variation present in the data can be explained by a spatial trend. The most significant trend model found to explain the variation of soil water values included sand content and was expressed by the following equations:

$\theta_{-33 \mathrm{kPa}}=0.4781-0.0036 \operatorname{Sand}(\%)$
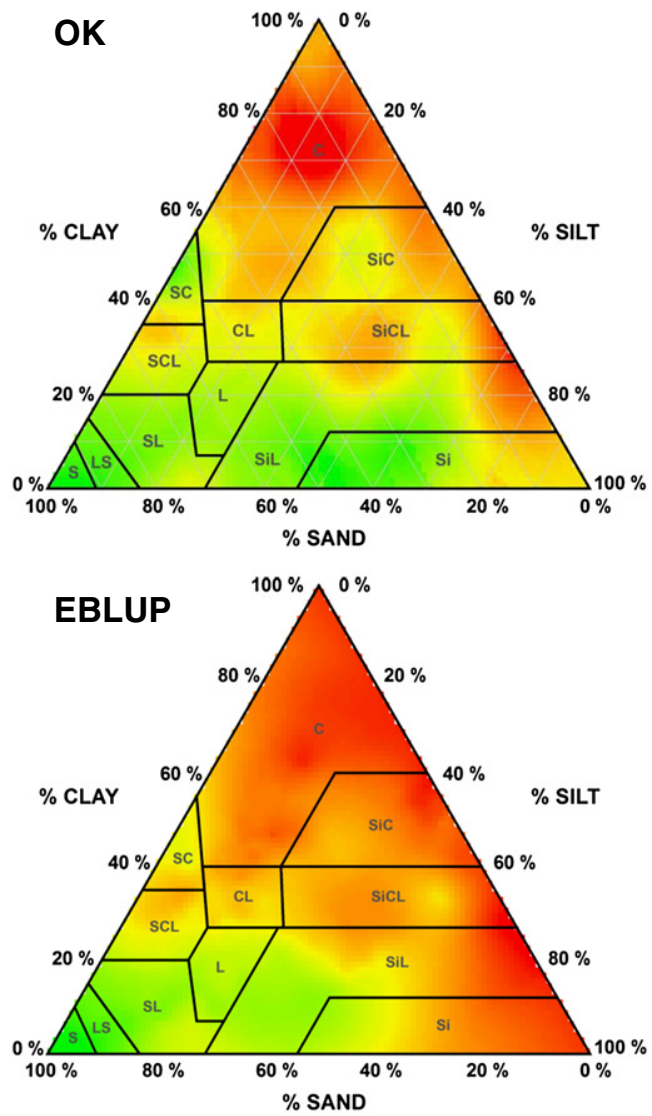
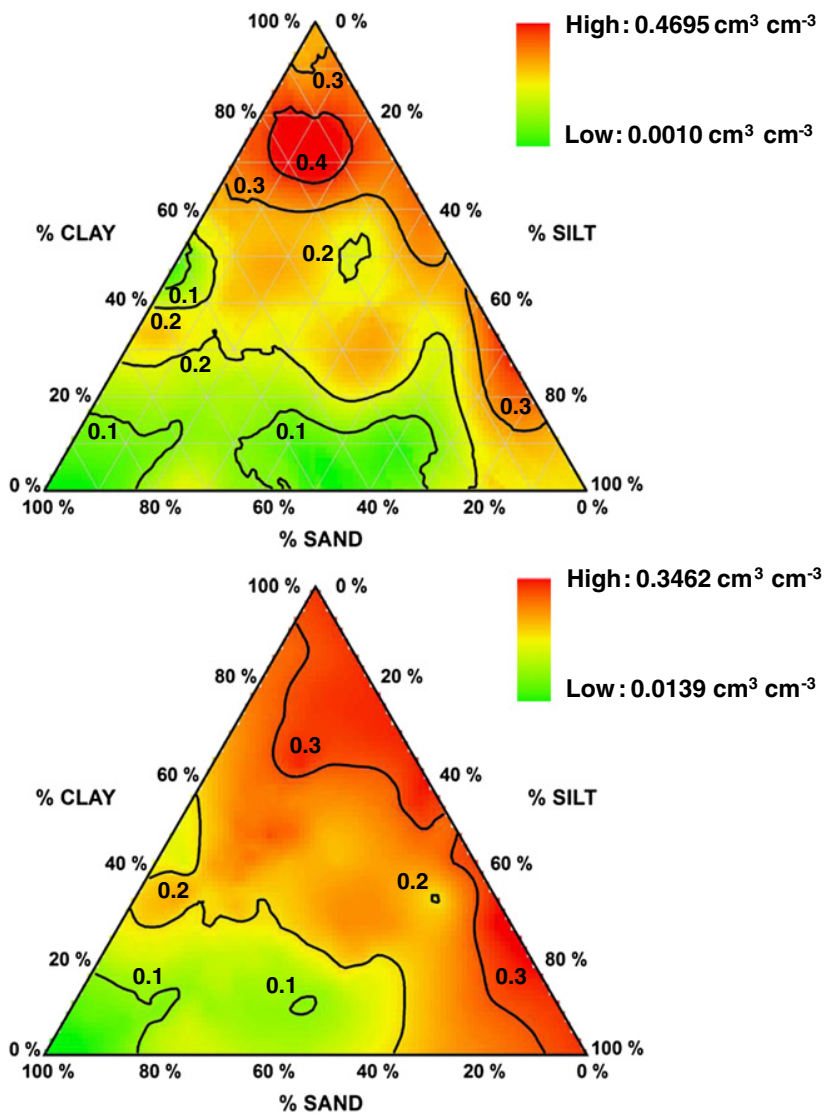

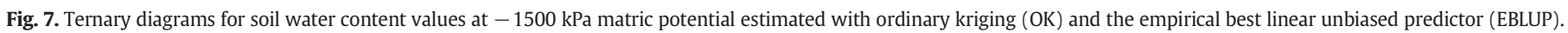
Figures on the left show the ISSS texture classes; figures on the right show the contour plots of the estimates. 

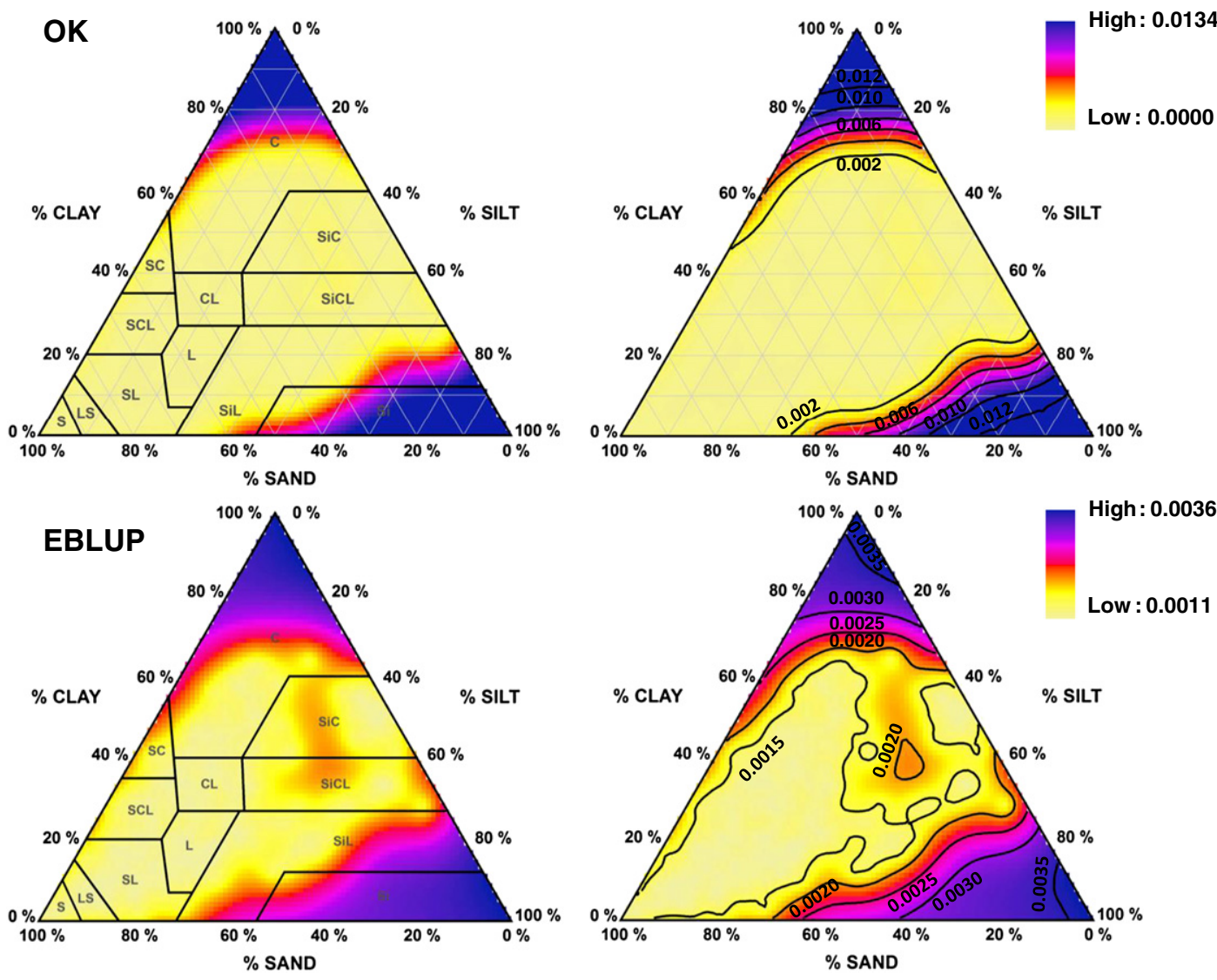

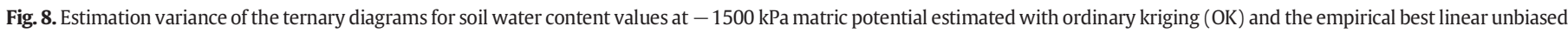
predictor (EBLUP). Figures on the left show the ISSS texture classes; figures on the right show the contour plots of the variance.

$\theta_{-1500 \mathrm{kPa}}=0.3206-0.0028 \operatorname{Sand}(\%)$.

These correspond to the optimum LMM fitted to $\theta_{-33} \mathrm{kPa}$ and $\theta_{-1500 \mathrm{kPa}}$ based on the AIC values. Lower AIC values were obtained for the spatial model when compared to the nonspatial model (assuming that model components are independent). These results showed that the models needed to include spatially correlated residuals to improve water retention prediction. All around, the residuals accounted for the variation of clay and silt that were not included in the trend model therefore reducing prediction uncertainty.

The estimated semivariogram parameters obtained for the residuals were, for $\theta_{-33 \mathrm{kPa}}, 0.0016 \%$ for the nugget value and $19.52 \%$ for the range. For $\theta_{-1500 \mathrm{kPa}}$, the results were $0.0009 \%$ for the nugget and $23.09 \%$ for the range. The fitted semivariograms are presented in Fig. 4. For $\theta_{-33 \mathrm{kPa}}$, the nugget value was quite large which may be interpreted as the residuals contributing less to explain the variation of water content when compared with the trend prediction. For $\theta_{-1500 \mathrm{kPa}}$ the nugget value is rather small, showing a strong correlation among residuals even at short distances. Hence, it is expected a higher contribution of the residuals when predicting the water content in these conditions.

\subsection{Ternary diagrams}

Fig. 5 presents the ternary diagram developed for estimating $\theta_{-33} \mathrm{kPa}$ from particle size distribution with the OK and EBLUP approaches. The resulting prediction variance is shown in Fig. 6. Both approaches revealed, as expected, that soil water retention values at $-33 \mathrm{kPa}$ matric potential were lower in the coarser texture classes and increased gradually with the increment of clay and silt contents. The EBLUP approach resulted in a smoother increase of $\theta_{-33} \mathrm{kPa}$ from the coarser to the fine and medium fine texture classes when compared with $\mathrm{OK}$ estimates. The predictions for the regions of the texture triangle where no information was available (e.g., the silty texture class, and the region of the texture triangle with clay content higher than 65\%) corresponded to much lower uncertainty values when compared with the OK approach (Fig. 6). This is probably due to the use of a spatial trend based on soil texture combined with spatially correlated residuals which also accounted for the texture information that was not included in the trend model. Although both approaches relate to kriging, the fact that EBLUP considers different contributions within the data results in better predictions for unsampled locations.

The mean $(\overline{\mathrm{x}})$ and standard deviation $(\sigma)$ values of the interpolated OK $\theta_{-33 \mathrm{kPa}}$ ternary diagram were 0.365 and $0.086 \mathrm{~cm}^{3} \mathrm{~cm}^{-3}$, respectively. The corresponding values obtained with the EBLUP approach were very similar $\left(\overline{\mathrm{x}}=0.362 \mathrm{~cm}^{3} \mathrm{~cm}^{-3} ; \sigma=0.082 \mathrm{~cm}^{3} \mathrm{~cm}^{-3}\right)$. The mean interpolated values were thus higher than the one registered in the development dataset $\left(0.287 \mathrm{~cm}^{3} \mathrm{~cm}^{-3}\right.$; Table 1$)$. The differences found resulted from the fact that the interpolated ternary diagrams estimated $\theta_{-33 \mathrm{kPa}}$ for all 4332 soil textures, including regions of the texture triangle where the development dataset had no information, thus producing significant differences in the classes of the interpolated histogram with higher water contents (not shown). In the OK approach, the estimation variance was very high in those regions, and thus local estimates of $\theta_{-33} \mathrm{kPa}$ were not realistic (Fig. 6). In the EBLUP approach, estimation variance was significantly lower than in the OK approach, likely more realistic, but nonetheless higher than in the regions where information was available. For the remaining regions where the ternary diagrams were well populated with information, the estimation variance was quite low in either approaches and estimates there were 
thus considered to be accurate (the region where information was available was hereafter defined as corresponding to the area of the texture triangle where the sum of $\theta_{-33} \mathrm{kPa}$ and $\theta_{-1500 \mathrm{kPa}}$ variance estimates $\left(\Sigma \sigma^{2}\right)$ provided by the OK estimator was $\left.\leq 0.003\right)$. In this region, the mean value given by both estimators (OK and EBLUP) and the mean value of the development dataset tended to be closer $(\overline{\mathrm{x}}=$ $0.334 \mathrm{~cm}^{3} \mathrm{~cm}^{-3}$ in the OK approach and $0.337 \mathrm{~cm}^{3} \mathrm{~cm}^{-3}$ in the EBLUP diagram).

Fig. 7 presents the interpolated $\theta_{-1500 \mathrm{kPa}}$ ternary diagrams developed with the OK and EBLUP approaches. The respective estimation variances are given in Fig. 8. In the OK ternary diagrams, soil water retention values at $-1500 \mathrm{kPa}$ matric potential were also lower in the coarser texture classes and seemed to increase progressively with the increase of clay content. However, soil water retention did not increase as gradually as registered for the $\theta_{-33} \mathrm{kPa}$ ternary diagram, since there were a few regions of the texture triangle (e.g., the area in the vicinity of the soil texture with $50 \%$ clay, $32 \%$ silt, and $18 \%$ sand) that clearly needed more information when estimating $\theta_{-1500 \mathrm{kPa}}$. The mean and standard deviation values of the interpolated OK $\theta_{-1500 \mathrm{kPa}}$ ternary diagram were 0.216 and $0.101 \mathrm{~cm}^{3} \mathrm{~cm}^{-3}$, respectively. The mean value was once again higher than the one in the development dataset $\left(0.162 \mathrm{~cm}^{3} \mathrm{~cm}^{-3}\right.$; Table 1$)$, but it was slightly lower where $\Sigma \sigma^{2} \leq 0.003\left(\bar{x}=0.202 \mathrm{~cm}^{3} \mathrm{~cm}^{-3}\right)$. In the EBLUP diagrams, $\theta_{-1500 \mathrm{kPa}}$ increase followed more clearly the increment of clay and silt. The increase of the water content throughout the texture triangle was again smoother than in the corresponding OK ternary diagram. The mean values in the entire EBLUP domain $\left(\bar{x}=0.225 \mathrm{~cm}^{3} \mathrm{~cm}^{-3}\right)$ and in the region where the triangle was more populated $(\overline{\mathrm{x}}=$ $0.206 \mathrm{~cm}^{3} \mathrm{~cm}^{-3}$ ) were again similar to those obtained with the $\mathrm{OK}$ approach, but $\sigma$ was lower $\left(\sigma=0.075 \mathrm{~cm}^{3} \mathrm{~cm}^{-3}\right)$ since the EBLUP estimator was able to better predict water content values in the regions of the texture triangle where information was scarcer due to the statistical relationship between the water contents and the texture constituents.

The results of the goodness-of-fit tests between measured and predicted water retention values at both matric potentials are presented in Table 2. Fig. 9 shows the corresponding scatter plots between measured and predicted values with the OK approach. The OK approach produced an acceptable prediction of $\theta_{-33} \mathrm{kPa}$ and $\theta_{-1500 \mathrm{kPa}}$, with ME values being very close to zero. RMSE values also showed that predictions were relatively accurate. RMSE were 0.040 and $0.033 \mathrm{~cm}^{3} \mathrm{~cm}^{-3}$ for the estimates of $\theta_{-33} \mathrm{kPa}$ and $\theta_{-1500 \mathrm{kPa}}$, respectively. The $\mathrm{R}^{2}$ values were considerably high and identical for both water contents

Table 2

Results of the statistical analysis between measured $\theta_{-33 \mathrm{kPa}}, \theta_{-1500 \mathrm{kPa}}$, and available water capacity (AWC) and estimates obtained from the ternary diagrams developed with ordinary kriging $(\mathrm{OK})$ and the empirical best linear unbiased predictor (EBLUP).

\begin{tabular}{|c|c|c|c|}
\hline \multirow[t]{2}{*}{ Statistics } & \multicolumn{3}{|c|}{ Volumetric water contents } \\
\hline & $\theta_{-33 \mathrm{kPa}}$ & $\theta_{-1500 \mathrm{kPa}}$ & AWC \\
\hline \multicolumn{4}{|l|}{ OK } \\
\hline $\mathrm{R}^{2}(-)$ & 0.788 & 0.802 & 0.541 \\
\hline $\operatorname{ME}\left(\mathrm{cm}^{3} \mathrm{~cm}^{-3}\right)$ & -0.001 & 0.001 & -1.71 \\
\hline $\operatorname{RMSE}\left(\mathrm{cm}^{3} \mathrm{~cm}^{-3}\right)$ & 0.040 & 0.033 & 32.17 \\
\hline \multicolumn{4}{|l|}{ EBLUP } \\
\hline $\mathrm{R}^{2}(-)$ & 0.788 & 0.792 & 0.539 \\
\hline $\operatorname{ME}\left(\mathrm{cm}^{3} \mathrm{~cm}^{-3}\right)$ & 0.002 & 0.002 & -0.12 \\
\hline $\operatorname{RMSE}\left(\mathrm{cm}^{3} \mathrm{~cm}^{-3}\right)$ & 0.040 & 0.034 & 32.08 \\
\hline \multicolumn{4}{|l|}{ Data grouping } \\
\hline $\begin{array}{l}\rho_{\mathrm{b}} \leq \overline{\mathrm{X}}_{\mathrm{FAO}} \text { texture class } \\
\mathrm{R}^{2}(-)\end{array}$ & 0.838 & - & 0.502 \\
\hline $\operatorname{ME}\left(\mathrm{cm}^{3} \mathrm{~cm}^{-3}\right)$ & 0.007 & - & 1.90 \\
\hline $\operatorname{RMSE}\left(\mathrm{cm}^{3} \mathrm{~cm}^{-3}\right)$ & 0.038 & - & 35.80 \\
\hline$\rho_{\mathrm{b}}>\overline{\mathrm{X}}_{\mathrm{FAO}}$ texture class & & & \\
\hline $\mathrm{R}^{2}(-)$ & 0.700 & - & 0.491 \\
\hline $\operatorname{ME}\left(\mathrm{cm}^{3} \mathrm{~cm}^{-3}\right)$ & -0.008 & - & -5.32 \\
\hline $\operatorname{RMSE}\left(\mathrm{cm}^{3} \mathrm{~cm}^{-3}\right)$ & 0.043 & - & 29.23 \\
\hline
\end{tabular}

$\rho_{\mathrm{b}}$, bulk density; $\overline{\mathrm{x}}$, average.
$\left(\mathrm{R}^{2}>0.78\right)$, indicating also a good agreement between measurements and predictions. However, data in the $\theta_{-1500} \mathrm{kPa}$ scatter plot was found to be slightly more dispersed than for $\theta_{-33} \mathrm{kPa}$. The EBLUP approach produced very similar results. Only, the RMSE and $\mathrm{R}^{2}$ found for $\theta_{-1500 \mathrm{kPa}}$ estimates were slightly worse (RMSE $=0.034 \mathrm{~cm}^{3} \mathrm{~cm}$ ${ }^{-3} ; \mathrm{R}^{2}=0.792$ ) than those obtained with $\mathrm{OK}$.

Table 3 shows the accuracy of published PTFs that are available for estimating soil hydraulic properties of Portuguese soils, and which estimates can be compared with those obtained with the ternary diagrams. We limited our comparison to PTFs that used partially or the entire dataset used in this study. The class-PTFs developed by Ramos et al. (2013) produced RMSE values that varied between 0.042 and $0.055 \mathrm{~cm}^{3} \mathrm{~cm}^{-3}$ when estimating $\theta_{-33 \mathrm{kPa}}$, and between 0.037 and $0.048 \mathrm{~cm}^{3} \mathrm{~cm}^{-3}$ when predicting $\theta_{-1500 \mathrm{kPa}}$. The best estimates, achieved with the class-PTFs developed after grouping data by ISSS texture classes and bulk density, can be comparable with the estimates given by the ternary diagrams. The point PTFs developed by Ramos et al. (2014) yielded RMSE values of 0.040 and $0.036 \mathrm{~cm}^{3} \mathrm{~cm}^{-3}$ also when predicting $\theta_{-33} \mathrm{kPa}$ and $\theta_{-1500 \mathrm{kPa}}$, respectively, thus producing very similar predictions to those given by OK and EBLUP estimates. On the other hand, the parametric PTFs developed by Gonçalves et al. (1997), Wösten et al. (1999), and Ramos et al. (2014) resulted in slightly higher RMSE values $\left(\geq 0.046 \mathrm{~cm}^{3} \mathrm{~cm}^{-3}\right)$ than those calculated with estimates given by the ternary diagrams. Hence, Table 3 shows that similar or even better predictions of $\theta_{-33} \mathrm{kPa}$ and $\theta_{-1500 \mathrm{kPa}}$ can be obtained with the ternary diagrams. The only predictor needed is the particle size distribution, while the other comparable PTFs require relatively more predictors than the needs of those diagrams. In terms of number of predictors, the ternary diagrams seem to be quite useful as they are the only PTFs that do not require bulk density, despite results are given in terms of volumetric water contents. Although this soil property is simple to measure, sampling undisturbed samples in different soil horizons/layers distributed over large areas in order to measure bulk density may be a very laborious task.

\subsection{Available water capacity}

Fig. 10 shows estimates of the available water capacity (AWC), calculated as the difference between the corresponding $\theta_{-33} \mathrm{kPa}$ and $\theta_{-1500 \mathrm{kPa}}$ obtained with OK and EBLUP methods, and setting soil depth to $1 \mathrm{~m}$ as reference for comparison between estimates. Fig. 10 also shows the AWC estimation variance, calculated by summing $\theta_{-33} \mathrm{kPa}$ and $\theta_{-1500 \mathrm{kPa}}$ estimation variances presented earlier in Figs. 6 and 8. AWC was calculated only for areas of the ternary diagrams where the AWC estimation variance was lower than $0.003\left(\Sigma \sigma^{2} \leq\right.$ 0.003 ). Therefore, we considered here only estimates that may be considered reliable and avoided extrapolations produced by the geostatistical estimators.

In the OK approach, the largest AWC estimates were obtained for the medium fine texture classes. The coarser texture classes and the soils with $65 \%$ clay content presented lower AWC. This seems to be in accord with Al Majou et al. (2008), where soils with high clay texture showed a high proportion of water that is not available for plants. However, the low estimates found for these latter soils were produced in a region of the ternary diagram where the estimation variance increased rapidly with the increase of the clay content, i.e., those predictions were near the limits of a region where the kriging estimator started to extrapolate information instead of interpolating it, and thus care should be taken when using that information. On the other hand, the EBLUP estimator, although revealing the same trends as observed in the OK diagrams, produced generally smaller AWC values for the selected region of the texture triangle. This estimator also provided much more interesting results for the extrapolated region (not shown). Fig. 11 shows the differences obtained between AWC values estimated with $\mathrm{OK}$ and EBLUP approaches. Positive values indicate larger OK estimates, while negative values correspond to larger EBLUP estimates. Nevertheless, 

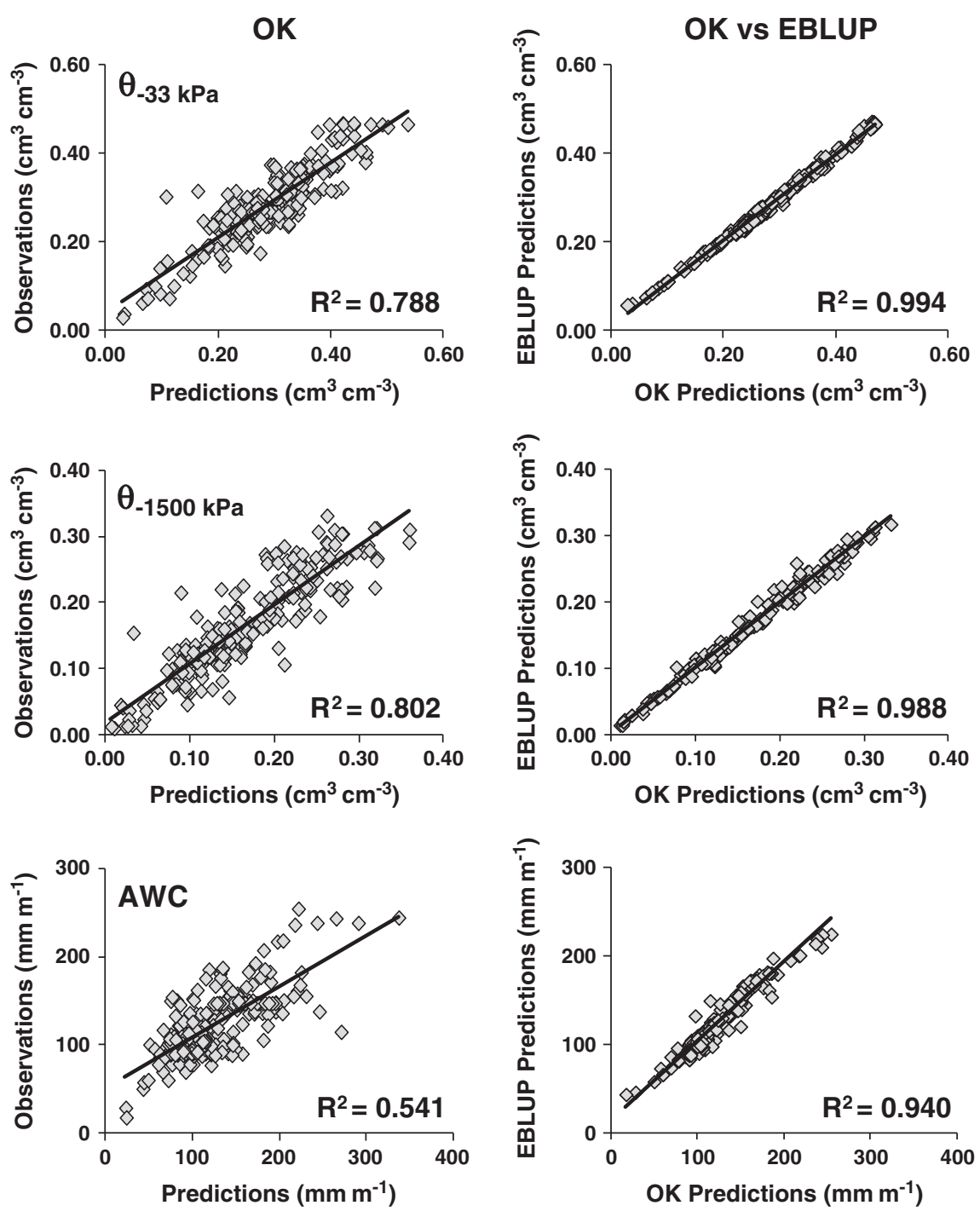

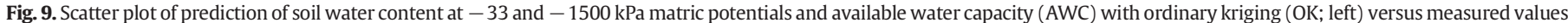
included in the validation dataset. Comparison of estimates with OK and the empirical best linear unbiased predictor (EBLUP; right side).

Table 3

Accuracy of published pedotransfer functions in the estimation of water retention values at -33 and $-1500 \mathrm{kPa}$ included in the database.

\begin{tabular}{llll}
\hline PTFs & Predictors & RMSE $\left(\mathrm{cm}^{3} \mathrm{~cm}^{-3}\right)$ \\
\cline { 3 - 4 } & & $\theta_{-33 \mathrm{kPa}}$ & $\theta_{-1500 \mathrm{kPa}}$ \\
\hline 1. Class-PTFs & & \\
Ramos et al. (2013) & FAO texture classes & 0.055 & 0.048 \\
& FAO texture classes + depth & 0.054 & 0.047 \\
& FAO texture classes + $\rho_{\mathrm{b}}$ & 0.049 & 0.047 \\
& FAO texture classes + depth $+\rho_{\mathrm{b}}$ & 0.047 & 0.046 \\
& ISSS texture classes & 0.049 & 0.039 \\
& ISSS texture classes + depth & 0.047 & 0.038 \\
Wösten et al. (1999) & ISSS texture classes + $\rho_{\mathrm{b}}$ & 0.042 & 0.037 \\
2. Continuous PTFs & FAO texture classes + depth & 0.063 & 0.051 \\
2.1. Point PTFs & & & \\
Ramos et al. (2014) & Si $i_{20} \mu \mathrm{m}, \mathrm{C}, \rho_{\mathrm{b}}, \mathrm{Z}$ & 0.040 & 0.036 \\
2.2. Parametric PTFs & & & \\
Gonçalves et al. (1997) & $\mathrm{CS}, \mathrm{FS}, \mathrm{Si}_{20} \mu \mathrm{m}, \mathrm{C}, \rho_{\mathrm{b}}, \mathrm{Z}, \mathrm{OM}, \mathrm{pH}$ & 0.046 & 0.053 \\
Wösten et al. (1999) & $\mathrm{Si}_{50} \mu \mathrm{m}, \mathrm{C}, \rho_{\mathrm{b}}, \mathrm{OM}, \mathrm{depth}$ & 0.049 & 0.045 \\
Ramos et al. (2014) & $\mathrm{CS}, \mathrm{FS}, \mathrm{Si}_{20} \mu \mathrm{m}, \mathrm{C}, \rho_{\mathrm{b}}, \mathrm{Z}$ & 0.084 & 0.051 \\
\hline
\end{tabular}

CS, coarse sand; FS, fine sand; $\mathrm{Si}_{20} \mu \mathrm{m}$, silt fraction at $20 \mu \mathrm{m}$; $\mathrm{Si}_{50 \mu \mathrm{m}}$, silt fraction at $50 \mu \mathrm{m}$; C, clay; $\rho_{\mathrm{b}}$, bulk density; $\mathrm{Z}$, mean depth; OM, organic matter; depth, qualitative variable having the values 1 (topsoils) and 0 (subsoils). the histograms presented in Fig. 12 show that the OK and EBLUP estimates of the AWC were relatively similar. OK produced an average value of $132.9 \mathrm{~mm} \mathrm{~m}^{-1}$, a variance of 2546.7, and kurtosis (0.18) and skewness (0.76) close to zero. EBLUP produced an average value of $131.4 \mathrm{~mm} \mathrm{~m}^{-1}$, a variance of 1548.3 , a kurtosis of -0.62 , and a skewness of 0.52 . This last estimator produced higher minimums and lower maximums. However, the Chi-square and Kolmogorov-Smirnov ( $p$ value $=0.00<0.01$ ) goodness-of-fit tests rejected the hypothesis that AWC estimates from either methods were normally distributed at a level of $99 \%$ confidence, likely because soil water content information in the very fine and medium fine texture classes was missing.

Table 2 shows the goodness-of-fit between calculated and estimated AWC values. Results obtained from both approaches produced again similar values, indicating an acceptable precision bias $\left(\mathrm{ME}<-0.12 \mathrm{~mm} \mathrm{~m}^{-1}\right)$ and a RMSE $>32.08 \mathrm{~mm} \mathrm{~m}^{-1}$. However, $\mathrm{R}^{2}$ values were more modest $(>0.534)$ than the ones obtained for

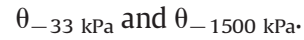

The ternary diagrams developed in this study $\left(\theta_{-33} \mathrm{kPa}, \theta_{-1500 \mathrm{kPa}}\right.$, and AWC) may potentially be useful for many scientific and technical domains, but they seem more relevant to agricultural water management, particularly irrigation management and scheduling. Various water balance models require the type of information provided by the 

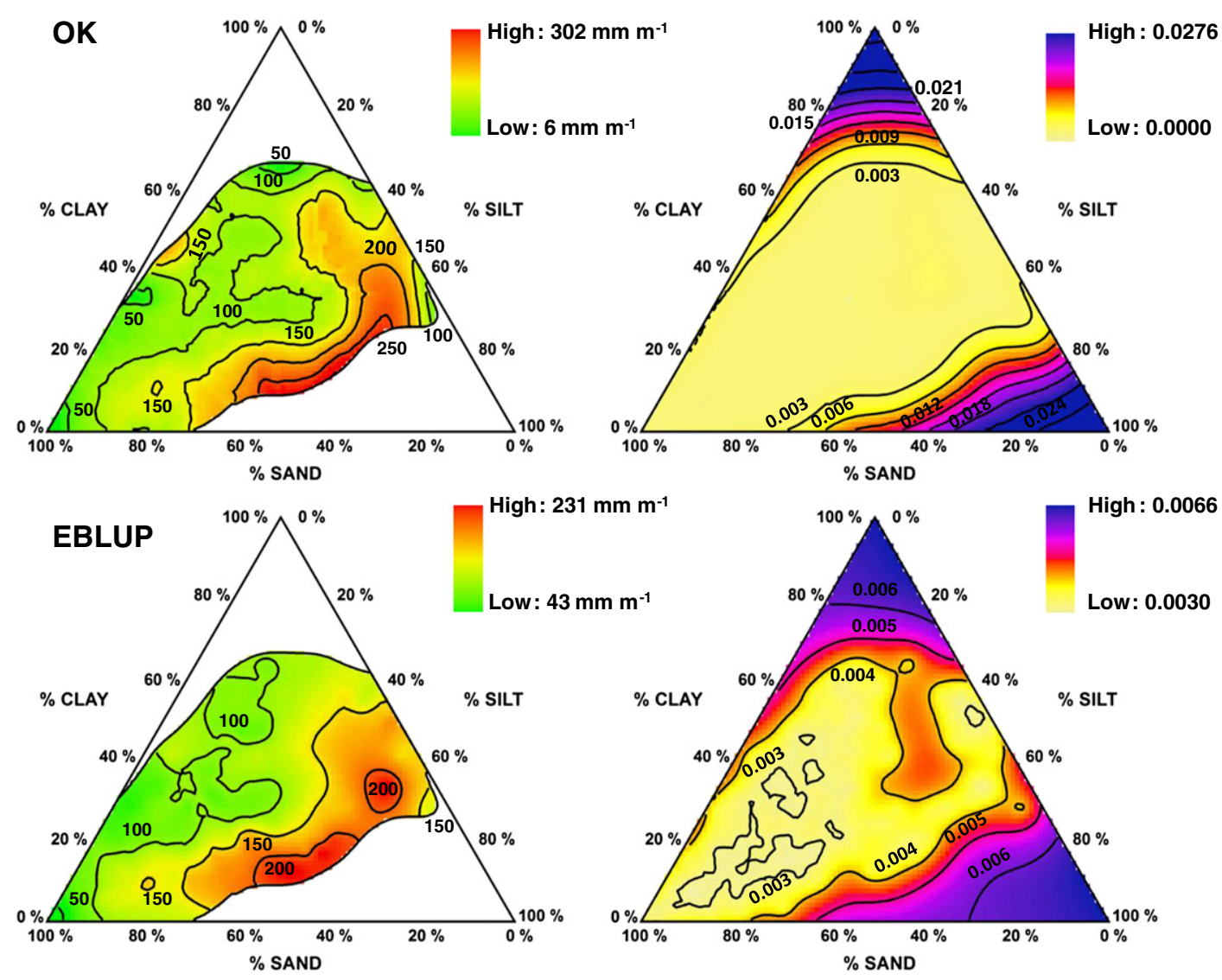

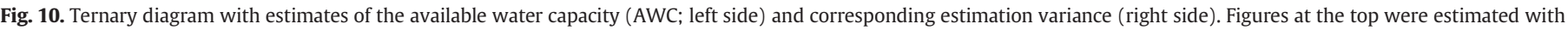
ordinary kriging $(\mathrm{OK})$; figure at the bottom were obtained with the empirical best linear unbiased predictor (EBLUP).

ternary diagrams here developed at point scale (Chopart et al., 2007; George et al., 2000; Khaledian et al., 2009; Liu et al., 1998; Rosa et al., 2012; Steduto et al., 2009). Those that are associated with a geographical information system and are applied at field scale (Fortes et al., 2005; Ojeda-Bustamante et al., 2007; Troch et al, 1993) can make even further use of the ternary diagrams here developed for estimating soil water retention properties of Portuguese soils.

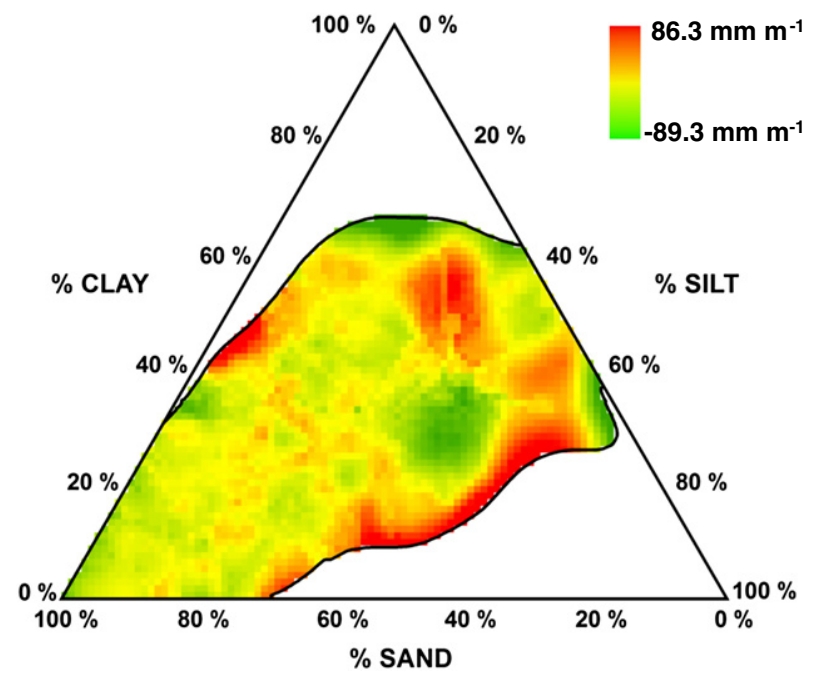

Fig. 11. Difference between estimates of the available water capacity calculated with ordinary kriging and the empirical best linear unbiased predictor.
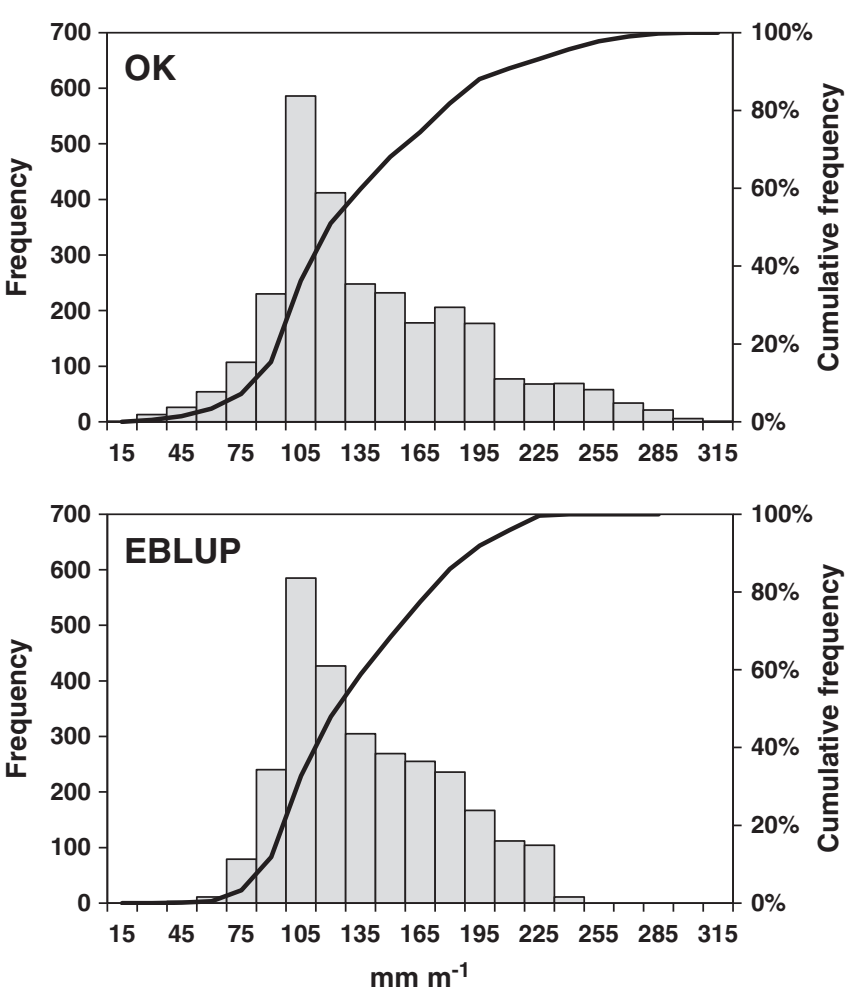

Fig. 12. Histogram with estimates of the available water capacity calculated from the ternary diagrams developed with ordinary kriging $(\mathrm{OK})$ and the empirical best linear unbiased predictor (EBLUP). 


\subsection{The effect of soil structure}

As discussed earlier, grouping data by bulk density $\left(\rho_{\mathrm{b}}\right)$ often contributes for reducing the variability of the datasets and ends up producing more accurate estimates of soil water retention at certain matric potentials (Wösten et al., 2001). This effect is normally more relevant for soil water retention values close to saturation, where the correlation with $\rho_{\mathrm{b}}$ is higher, than for water retention values in the drier end of the soil-water retention curve (Al Majou et al., 2008; Bruand et al., 2003; Ramos et al., 2013). This is also the case of the dataset used in this study, in which the correlation between $\rho_{\mathrm{b}}$ and $\theta_{-33} \mathrm{kPa}$ reached -0.531 , while between $\rho_{\mathrm{b}}$ and $\theta_{-1500 \mathrm{kPa}}$ was only -0.302 .

Fig. 13 shows the $\theta_{-33} \mathrm{kPa}$ and AWC ternary diagrams after grouping the development dataset by bulk density. The development dataset was first grouped by FAO texture classes, and then data was divided based on the average $\rho_{b}$ values of the corresponding FAO texture classes. Thus, for samples included in the coarse, medium, fine, medium fine, and very fine texture classes the cutting $\rho_{\mathrm{b}}$ values were $1.56,1.54$, $1.41,1.30$, and $1.35 \mathrm{~g} \mathrm{~cm}^{-3}$, respectively. The sub-dataset with the lowest $\rho_{\mathrm{b}}$ values ended up containing 200 samples, while the subdataset with the highest $\rho_{\mathrm{b}}$ values included 242 samples. The ternary diagrams were developed using OK only since our objective here is merely demonstrative. The variograms used are also described in Fig. 3. The AWC diagrams were calculated as the difference between each of the $\theta_{-33} \mathrm{kPa}$ diagrams developed after grouping data by $\rho_{\mathrm{b}}$ and the $\theta_{-1500 \mathrm{kPa}}$ ternary diagram presented in Fig. 7 (the one developed with the OK approach). The reference soil depth was again $1 \mathrm{~m}$.

Despite our dataset being relatively too small to obtain two distinct subsets reasonably distributed throughout the texture triangle, the ternary diagrams obtained after grouping data by $\rho_{b}$ were able to show the effect of soil structure on soil water retention estimates. The $\theta_{-33 \mathrm{kPa}}$ ternary diagram developed from the dataset with the lowest $\rho_{\mathrm{b}}$ values clearly showed a larger area with water retention values higher than $0.4 \mathrm{~cm}^{3} \mathrm{~cm}^{-3}$, located in the region of the texture triangles corresponding to the fine texture classes, than the corresponding diagram produced with the highest $\rho_{\mathrm{b}}$ values. The negative correlation between $\theta_{-33} \mathrm{kPa}$ and $\rho_{\mathrm{b}}$ was also notorious in the AWC estimates produced from each sub-dataset. The average AWC was 147.4 and $110.0 \mathrm{~mm} \mathrm{~m}^{-1}$ in the region of the ternary diagrams developed from the subsets with the lowest and highest values of $\rho_{\mathrm{b}}$, respectively, and again where $\Sigma \sigma^{2} \leq 0.003$ (as explained above). Moreover, total variance in the variogram fitted to one of the subsets actually decreased and hypothesized earlier (Fig. 3). The goodness-of-fit tests, calculated after also dividing the validation set using the same criteria as the one used for splitting the development dataset, showed better ME, RMSE and $\mathrm{R}^{2}$ for $\theta_{-33} \mathrm{kPa}$ estimates obtained with the subset containing the lowest $\rho_{b}$ values, i.e., with the subset where the effect of soil structure was more notorious (Table 2). For AWC, the goodness-of-fit tests obtained were slightly worse than those calculated before splitting data. Thus, like for the traditional PTFs, grouping data seems here to be also a promising technique to improve water content estimates in the ternary diagrams. However, this should be further tested using a much larger, well distributed soil database than the one currently available in Portugal and used in this study.

\section{Conclusions}

The OK and EBLUP approaches were able to provide reliable estimates of $\theta_{-33 \mathrm{kPa}}, \theta_{-1500 \mathrm{kPa}}$, and AWC using only the relative proportion of different grain size particles (sand, silt, and clay) as input

\section{$\begin{array}{ll}\text { a) } \theta_{-33 \mathrm{KPa}}\left(\rho_{\mathrm{b}} \leq \overline{\mathrm{x}}_{\text {FAO texture classes }}\right) & \text { b) } \theta_{-33 \mathrm{KPa}}\left(\rho_{\mathrm{b}}>\overline{\mathrm{x}}_{\text {FAO texture classes }}\right)\end{array}$}

C) $\theta_{-33 \mathrm{kPa}}(\mathrm{a}-\mathrm{b})$
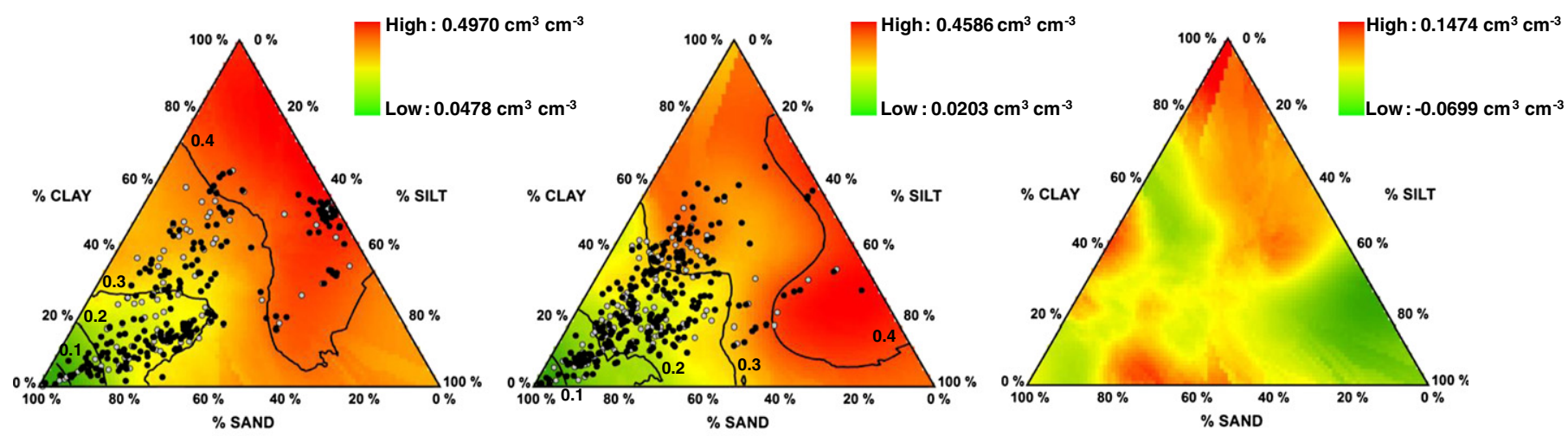

d) AWC $\left(\rho_{b} \leq \bar{x}_{\text {FAO texture classes }}\right)$

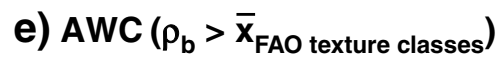

f) $\operatorname{AWC}(a-b)$

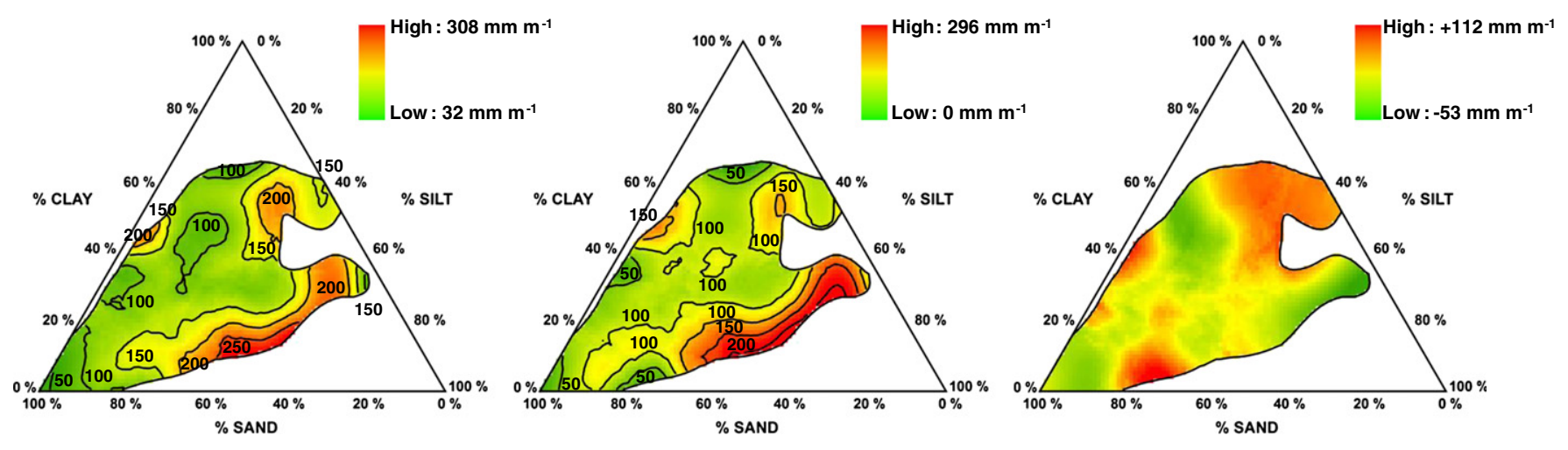

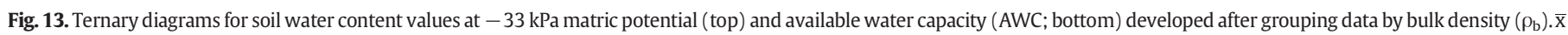
corresponds to the average $\rho_{\mathrm{b}}$ in each of the FAO texture classes. 
data. Predictions were given for a continuous $1 \%$ variation grid of the particle size distribution. Thus, the ternary diagrams may be considered a new type of class PTFs. The OK method was helpful to understand which estimates of the soil water retention were valid based on the values of the estimation variance, and thus extrapolations were avoided. The EBLUP method provided a different interpretation for that data and allowed us to incorporate more information in the final predictions. However, it produced similar predictions for $\theta_{-33} \mathrm{kPa}$ and $\theta_{-1500 \mathrm{kPa}}$ as those obtained with OK. The main advantage of EBLUP was that it was able to significantly reduce uncertainty in regions of the texture diagram where information was scarcer.

The RMSE values were lower than 0.040 and $0.034 \mathrm{~cm}^{3} \mathrm{~cm}^{-3}$ when comparing the estimates provided by the $\theta_{-33} \mathrm{kPa}$ and $\theta_{-1500 \mathrm{kPa}}$ ternary diagrams, respectively, and the measured values included in the validation dataset. The OK and EBLUP approaches produced similar RMSE values. Those values are comparable to the estimates provided by most of the available PTFs for estimating soil water retention properties of Portuguese soils. The ternary diagrams may thus serve as simplified tools for estimating those properties from particle size distribution and eventually serve as an alternative to the traditional statistical regression and data mining techniques used to derive PTFs.

\section{Acknowledgments}

This research was performed within the framework of the Project PTDC/AGR-AAM/098100/2008 of the Fundação para a Ciência e a Tecnologia (FCT). T. B. Ramos was funded by the FCT grant SFRH/BD/ $60363 / 2009$. A. Horta was funded by the Richard Claude Mankin scholarship provided by the University of Sydney.

\section{References}

Al Majou, H., Bruand, A., Duval, O., Le Bas, C., Vautier, A., 2008. Prediction of soil water retention properties after stratification by combining texture, bulk density and the type of horizon. Soil Use Manag. 24, 383-391. http://dx.doi.org/10.1111/j.1475 2743.2008.00180.x.

Bormann, H., 2007. Analysis of the suitability of the German soil texture classification for the regional scale application of physical based hydrological model. Adv. Geosci. 11 7-13. http://dx.doi.org/10.5194/adgeo-11-7-2007.

Bouma, J., 1989. Using soil survey data for quantitative land evaluation. Adv. Soil Sci. 9, 177-213.

Bruand, A., Pérez Fernandez, P., Duval, O., 2003. Use of class pedotransfer functions based on texture and bulk density of clods to generate water retention curves. Soil Use Manag. 19, 232-242. http://dx.doi.org/10.1111/j.1475-2743.2003.tb00309.x.

Chopart, J.L., Mézino, M., Aure, F., Le Mézo, L., Mété, M., Vauclin, M., 2007. OSIRI: a simple decision-making tool for monitoring irrigation of small farms in heterogeneous environments. Agric. Water Manag. 87, 128-138. http://dx.doi.org/10.1016/j.agwat. 2006.06.023.

CMRP (Centro de Modelização de Reservatórios Petrolíferos), 2000. Manual do geoMS v1 0 . Instituto Superior Técnico, Lisboa, Portugal.

Dane, J.H., Hopmans, J.W., 2002. Pressure plate extractor. In: Dane, J.H., Topp, G.C. (Eds.), Methods of Soil Analysis, Part 4, Physical Methods. Soil Science Society of America Book Series, Soil Science Society of America, Madison, Wisconsin, pp. 688-690.

Dane, J.H., Topp, G.C., 2002. Methods of soil analysis. Part 4, physical methods. Soil Science Society of America Book Series, Soil Science Society of America, Madison, Wisconsin.

Diggle, P.J., Ribeiro Jr., P.J., 2007. Model Based Geostatistics. Springer, New York.

FAO, 2006. World reference base for soil resources. A framework for internationa classification, correlation and communication. World Soil Resources Report 103, Food and Agriculture Organization of the United Nations, Rome, Italy.

Fortes, P.S., Platonov, A.E. Pereira, L.S., 2005. GISAREG - a GIS based irrigation scheduling simulation model to support improved water use. Agric. Water Manag. 77, 159-179. http://dx.doi.org/10.1016/j.agwat.2004.09.042.

George, B.A., Shende, S.A., Raghuwanshi, N.S., 2000. Development and testing of an irrigation scheduling model. Agric. Water Manag. 46, 121-136. http://dx.doi.org/10.1016/ S0378-3774(00)00083-4.

Gomes, M.P., Silva, A.A., 1962. Um novo diagrama triangular para a classificação básica da textura do solo. Garcia Orta 10, 171-179.

Gonçalves, M.C., Pereira, L.S., Leij, F.J., 1997. Pedo-transfer functions for estimating unsaturated hydraulic properties of Portuguese soils. Eur. J. Soil Sci. 48, 387-400. http://dx.doi.org/10.1111/j.1365-2389.1997.tb00205.x.

Gonçalves, M.C. Ramos, T.B., Pires, F.P. 2011. Base de dados georreferenciada das propriedades do solo. In: Coelho, P.S., Reis, P. (Eds.), Agrorrural. Contributos Científicos. Instituto Nacional dos Recursos Biológicos, Oeiras, Portugal, pp. 564-574

Goovaerts, P., 1997. Geostatistics for Natural Resources Evaluation. Oxford University Press, New York.
Goovaerts, P., 1999. Geostatistics in soil science: state-of-the-art and perspectives. Geoderma 89, 1-45. http://dx.doi.org/10.1016/S0016-7061(98)00078-0.

Goovaerts, P., 2001. Geostatistical modeling of uncertainty in soil science. Geoderma 103, 3-26. http://dx.doi.org/10.1016/S0016-7061(01)00067-2.

Gupta, S.C., Larson, W.E., 1979. Estimating soil water retention characteristics from particle size distribution, organic matter content, and bulk density. Water Resour. Res. 15, 1633-1635. http://dx.doi.org/10.1029/WR015i006p01633.

Haghverdi, A., Cornelis, W.M., Ghahraman, B., 2012. A pseudo-continuous neural network approach for developing water retention pedotransfer functions with limited data. J. Hydrol. 442-443, 46-54. http://dx.doi.org/10.1016/j.jhydrol.2012.03.036.

Journel, A.G., Huijbregts, C.J., 1978. Mining Geostatistics. Academic Press, New York (600 pp.).

Khaledian, M.R., Mailhol, J.C., Ruelle, P., Rosique, P., 2009. Adapting PILOTE model for water and yield management under direct seeding system: the case of corn and durum wheat in a Mediterranean context. Agric. Water Manag. 96, 757-770. http:// dx.doi.org/10.1016/j.agwat.2008.10.011.

Lark, R.M., Cullis, B.R., Welham, S.J., 2006. On spatial prediction of soil properties in the presence of a spatial trend: the empirical best linear unbiased predictor (E-BLUP) with REML. Eur. J. Soil Sci. 57, 787-799. http://dx.doi.org/10.1111/j.1365-2389.2005.00768.x.

Liu, Y., Teixeira, J.L., Zhang, H.J., Pereira, L.S., 1998. Model validation and crop coefficients for irrigation scheduling in the North China Plain. Agric. Water Manag. 36, 233-246. http://dx.doi.org/10.1016/S0378-3774(97)00051-6.

McBratney, A.B., Minasny, B., Cattle, S.R., Vervoort, R.W., 2002. From pedotransfer functions to soil inference systems. Geoderma 109, 41-73. http://dx.doi.org/10. 1016/S0016-7061(02)00139-8

Nemes, A., Rawls, W.J., 2006. Evaluation of different representations of the particle-size distribution to predict soil water retention. Geoderma 132, 47-58. http://dx.doi.org/ 10.1016/j.geoderma.2005.04.018

Nemes, A., Rawls, W.J., Pachepsky, Y.A., 2006. Use of a nonparametric nearest-neighbor technique to estimate soil water retention. Soil Sci. Soc. Am. J. 70, 327-336. http:// dx.doi.org/10.2136/sssaj2005.0128.

Ojeda-Bustamante, W., González-Camacho, J.M., Sifuentes-Ibarra, E., Isidro, E., RendónPimentel, L., 2007. Using spatial information systems to improve water management in México. Agric. Water Manag. 89, 81-88. http://dx.doi.org/10.1016/j.agwat.2006.11. 002

Pachepsky, Y.A., Rawls, W.J., 2004. Development of Pedotransfer Functions in Soil Hydrology. Elsevier, Amsterdam, The Netherlands.

Ramos, T.B., Gonçalves, M.C., Brito, D., Martins, J.C., Pereira, L.S., 2013. Development of class pedotransfer functions for integrating water retention properties into Portuguese soil maps. Soil Res. 51. http://dx.doi.org/10.1071/SR12347.

Ramos, T.B., Gonçalves, M.C., Martins, J.C., Pereira, L.S., 2014. Comparação de diferentes funções de pedotransferência para estimar as propriedades hidráulicas em Portugal. In: Gonçalves, M.C., Ramos, T.B., Martins, J.C. (Eds.), Proceedings do Encontro Anual de Ciência do Solo, 26-28 Julho. Instituto Nacional de Investigação Agrária e Veterinária, Oeiras, Portugal. ISBN: 978-972-579-039-7, pp. 29-34.

Rawls, W.J., Brakensiek, D.L., 1985. Prediction of soil water properties for hydrologic modelling. In: Jones, E., Ward, T.J. (Eds.), Watershed Management in the Eighties (Proceedings). ASCE, Denver, Colorado, pp. 293-299.

Romano, N., Santini, A., 2002. Water retention and storage. Field. In: Dane, J.H., Topp, G.C. (Eds.), Methods of Soil Analysis, Part 4, Physical Methods. Soil Science Society of America Book Series, Soil Science Society of America, Madison, Wisconsin, pp. 721-738.

Romano, N., Hopmans, J.W., Dane, J.H., 2002. Suction table. In: Dane, J.H., Topp, G.C. (Eds.), Methods of Soil Analysis, Part 4, Physical Methods. Soil Science Society of America Book Series, Soil Science Society of America, Madison, Wisconsin, pp. 692-698.

Rosa, R., Paredes, P., Rodrigues, G.C., Alves, I., Fernando, R.M., Pereira, L.S., Allen, R.G., 2012. Implementing the dual crop coefficient approach in interactive software. 1. Background and computational strategy. Agric. Water Manag. 103, 8-24. http://dx.doi. org/10.1016/j.agwat.2011.10.013

Saxton, K.E., Rawls, W.J., 2006. Soil water characteristics estimates by texture and organic matter for hydrologic solutions. Soil Sci. Soc. Am. J. 70, 1569-1578. http://dx.doi.org/ 10.2136/sssaj2005.0117.

Saxton, K.E., Rawls, W.J., Romberger, J.S., Papendick, R.I., 1986. Estimating generalized soil water characteristics from texture. Soil Sci. Soc. Am. J. 50, 1031-1036. http://dx.doi. org/10.2136/sssaj1986.03615995005000040039x.

Schaap, M.G., Leij, F.J., 1998. Database-related accuracy and uncertainty of pedotransfer functions. Soil Sci. 163, 765-779. http://dx.doi.org/10.1097/00010694-199810000-00001.

Schaap, M.G., Leij, F.J., van Genuchten, M.Th, 2001. ROSETTA: a computer program for estimating soil hydraulic parameters with hierarchical pedotransfer functions. J. Hydrol. 251, 163-176. http://dx.doi.org/10.1016/S0022-1694(01)00466-8.

Steduto, P., Hsiao, T.C., Raes, D., Fereres, E., 2009. AquaCrop - the FAO crop model to simulate yield response to water: I. Concepts and underlying principles. Agron. J. 101, 426-437. http://dx.doi.org/10.2134/agronj2008.0139s.

Troch, P.A., Mancini, M., Paniconi, C., Wood, E.F., 1993. Evaluation of a distributed catchment scale water balance model. Water Resour. Res. 29, 1805-1817. http://dx.doi. org/10.1029/93WR00398

Twarakavi, N.K.C., Šimůnek, J., Schaap, M.G., 2010. Can texture-based classification optimally classify soils with respect to soil hydraulics? Water Resour. Res. 46, W01501. http://dx.doi.org/10.1029/2009WR007939.

van Genuchten, M.Th, 1980. A closed form equation for predicting the hydraulic conductivity of unsaturated soils. Soil Sci. Soc. Am. J. 44, 892-898. http://dx.doi.org/10.2136/ sssaj1980.03615995004400050002x.

Vereecken, H., Maes, J., Feyen, J., Darius, P., 1989. Estimating the soil moisture retention characteristics from texture, bulk density, and carbon content. Soil Sci. $148,389-403$.

Vereecken, H., Weynants, M., Javaux, M., Pachepsky, Y., Schaap, M.G., van Genuchten, M. Th, 2010. Using pedotransfer functions to estimate the van Genuchten-Mualem soil 
hydraulic properties: a review. Vadose Zone J. 9, 795-820. http://dx.doi.org/10.2136/ vzj2010.0045.

Webster, R., Oliver, M.A., 2007. Geostatistics for Environmental Scientists. Wiley, Chichester, UK (330 pp.).

Wösten, J.H.M., Finke, P.A., Jansen, M.J.W., 1995. Comparison of class and continuous pedotransfer functions to generate soil hydraulic characteristics. Geoderma 66, 227-237. http://dx.doi.org/10.1016/0016-7061(94)00079-P.

Wösten, J.H.M., Lilly, A., Nemes, A., Le Bas, C., 1999. Development and use of a database of hydraulic properties of European soils. Geoderma 90, 169-185. http://dx.doi.org/10. 1016/S0016-7061(98)00132-3.
Wösten, J.H.M., Pachepsky, Y.A., Rawls, W.J., 2001. Pedotransfer functions: bridging the gap between available basic soil data and missing soil hydraulic characteristics. J. Hydrol. 251, 123-150. http://dx.doi.org/10.1016/S0022-1694(01)00464-4.

Yates, S.R., Warrick, A.W., 2002. Geostatistics. In: Dane, J.H., Topp, G.C. (Eds.), Methods of Soil Analysis, Part 4, Physical Methods. Soil Science Society of America book Series, Soil Science Society of America, Madison, Wisconsin, pp. 81-118. 